\title{
El Boletín de la Biblioteca Nacional de Criminología y Ciencias Afines (1926-1929): Eusebio Gómez y la Penitenciaría Nacional de Buenos Aires)
}

The Boletín de la Biblioteca Nacional de Criminología y Ciencias Afines (1926-1929). Eusebio Gómez and the Buenos Aires National Penitentiary) Le Boletín de la Biblioteca Nacional de Criminología y Ciencias Afines (1926-1929). Eusebio Gómez et le Péninentier National de Buenos Aires

\section{Esteban González}

\section{OpenEdition}

\section{Journals}

Edición electrónica

URL: http://journals.openedition.org/rhj/2083

DOI: $10.4000 /$ rhj.2083

ISSN: 0719-4153

Editor

ACTO Editores Ltda

Referencia electrónica

Esteban González, «El Boletín de la Biblioteca Nacional de Criminología y Ciencias Afines (1926-1929):

Eusebio Gómez y la Penitenciaría Nacional de Buenos Aires) 》, Revista Historia y Justicia [En línea],

12 | 2019, Publicado el 29 mayo 2019, consultado el 05 julio 2019. URL : http://

journals.openedition.org/rhj/2083 ; DOI : 10.4000/rhj.2083

Este documento fue generado automáticamente el 5 julio 2019.

Revista Historia y Justicia 


\section{El Boletín de la Biblioteca Nacional de Criminología y Ciencias Afines (1926-1929): Eusebio Gómez y la Penitenciaría Nacional de Buenos Aires)}

The Boletín de la Biblioteca Nacional de Criminología y Ciencias Afines (1926-1929). Eusebio Gómez and the Buenos Aires National Penitentiary) Le Boletín de la Biblioteca Nacional de Criminología y Ciencias Afines (1926-1929). Eusebio Gómez et le Péninentier National de Buenos Aires

Esteban González

\section{NOTA DEL EDITOR}

Recibido: 23 de enero de 2019 / Aceptado: 05 de mayo de 2019

\section{Introducción}

1 La presencia en Argentina de una publicación focalizada en la cuestión penitenciaria respondió, hasta la década de 1930, a una cronología discontinua. Las publicaciones periódicas que dieron cabida a las preocupaciones acerca de la gestión de las prisiones se enmarcaron, salvo escasas excepciones, en proyectos vinculados al estudio sintomático de la delincuencia y las prevenciones del delito más que al tratamiento punitivo. Movilizadas en gran parte por la capacidad argumentativa de la criminología europea -cuya incorporación por estas tierras no estuvo exenta de cuestionamientos y adaptaciones locales-, las revistas dedicaron espacios irregulares al tratamiento penitenciario. 
El Boletín de la Biblioteca Nacional de Criminología y Ciencias Afines (en adelante, BBNCCA) se centró en difundir los abordajes teóricos y prácticos acerca de la gestión penitenciaria, proveyendo a sus lectores de una importante síntesis de las legislaciones y prisiones locales y del mundo. El proyecto emprendido por el director de la Penitenciaría Nacional, Eusebio Gómez (1880-1953) gozó de importantes reconocimientos internacionales durante los tres años que duró la publicación, que se sumaron a las extensas referencias realizadas fuera de las fronteras nacionales acerca del penal argentino.

El objetivo de este texto es indagar de manera exploratoria en el BBNCCA, una publicación que aún no ha sido investigada con exhaustividad, e intentar demostrar la importancia de la publicación para la emergencia de saberes penitenciarios. Por lo tanto, pretendemos contextualizar la revista dentro de la trayectoria intelectual de su director, Eusebio Gómez y su paso por el irregular campo de las revistas criminológicas, atendiendo en las características principales de las publicaciones periódicas pioneras en abordar la administración penitenciaria local y foránea. En segundo lugar, indagaremos en las características formales del boletín, priorizando las cuestiones relativas a la administración penitenciaria. Por último, repasaremos la gestión de Gómez como director de la Penitenciaría Nacional a partir de la documentación presentada en el BBNCCA.

\section{Eusebio Gómez a través de las revistas argentinas: 1900-1930}

4 Cuando Eusebio Gómez publicó su libro Criminología Argentina (1912) - una guía referencial de las publicaciones locales escritas acerca de la materia -, los textos que conformaban el racconto bibliográfico reseñado casi en su totalidad por el autor sumaban algo más de mil títulos, todos ellos fechados desde la segunda mitad del siglo XIX. Los criterios de clasificación adoptados por el abogado rosarino revelaban los imprecisos límites del saber criminológico, aspecto característico de las ciencias sociales en el periodo ${ }^{1}$. Algunas de aquellas categorías utilizadas por Gómez como "Medicina Legal", "Derecho Penal e Internacional", "Policía: Dactiloscopía e identificación en general" dan cuenta del carácter interdisciplinario de la propuesta científica nacida en Italia, mientras que otras categorías como "De las penas en general; cuestiones relativas a las penas; pena de muerte", "Responsabilidad; circunstancias eximentes, atenuantes y agravantes" o "Ciencia y legislación penitenciarias" describen aquella pretensiosa presencia de la criminología en todos los eslabones de la "cuestión criminal", por utilizar el concepto esbozado por Máximo Sozzo ${ }^{2}$. Los criminólogos estarían presentes en todos los aspectos vinculados al crimen: desde el delito cometido (o antes) hasta la concreción y efectivo cumplimiento del castigo sancionado.

5 Gómez decidió colocar al final de la compilación una brevísima suma de títulos categorizados como "Revistas". El dato llama la atención por dos motivos: el escaso número de publicaciones referidas en contraste con las anteriores secciones (Gómez solo reseña tres revistas, dos de ellas ya interrumpidas para el año de publicación del libro), y el criterio de selección utilizado para emprender un recorte tan reducido, marginando a otras publicaciones mas heterodoxas, como La semana médica o Revista de Policía - pero que no estuvieron exentas de la presencia teórica de los emergentes criminólogos -, o desaparecidos proyectos como la Revista Criminal ${ }^{3}$. Si tenemos en cuenta que Gómez para 1912 ya cumplía una década como egresado de la carrera de abogacía en la Facultad de 
Derecho y Ciencias Sociales de la Universidad de Buenos Aires, el amplio repertorio de publicaciones vigentes no podría haber sido desconocido por el autor de Criminología Argentina $a^{4}$.

6 En la actualidad, lo escrito por Gómez con respecto a las revistas no es difícil de contrastar, ya que durante las últimas décadas las publicaciones periódicas paulatinamente se irán conformando en una fuente documental de creciente indagación, proponiéndose como un objeto de estudio predilecto por varios investigadores ${ }^{5}$. La temprana conformación de proyectos editoriales de estas características permitió revisar la gran cantidad de perspectivas que se intersectan en las revistas, que fueron durante el periodo analizado una referencia ineludible para los expertos y funcionarios estatales. Así, las revistas fueron a menudo un corpus argumentativo para el trazado de políticas públicas con distintos alcances.

7 La centralidad de Buenos Aires marcará doblemente los emprendimientos finiseculares de publicaciones periódicas de la cuestión criminal: si fueron expertos porteños los que dirigieron y/o colaboraron en las primeras publicaciones, también serán instituciones de la capital de la provincia las que editen sus revistas y boletines. En este sentido, la Penitenciaría de Buenos Aires, nacionalizada en 1880, será probablemente el punto de referencia más relevante de los cautivados por aquella incipiente criminología, además del escenario estructural para varias publicaciones. A poco tiempo de su puesta en funcionamiento en 1877, la prisión porteña se convirtió no solo en un espacio emblemático de diseño y aplicación de políticas públicas, sino también en el polo central del sistema penitenciario argentino. Asimismo, el territorio ocupado por el ambicioso edificio volvía a la institución un elemento inevitable para los ojos de cualquier transeúnte: se trataba de una superficie de 122.000 metros cuadrados, que con una muralla que alcanzaba los 7 metros albergaba los múltiples pabellones y locales de producción. Localizada en el actual barrio de Palermo, existían allí casi setecientas celdas destinadas a penados, sin incluir el centenar de camas para los cuerpos de guardia: esta configuración perduró sin muchas alteraciones hasta principios de los años sesenta cuando finalmente fue demolida. Su costo de producción de $45.863 .468 \mathrm{~m} / \mathrm{n}$ la volvió uno de los edificios más costosos en América Latina, no solo en los presupuestos sino en su mantenimiento día a día ${ }^{6}$.

8 Más cerca del siglo XX, la premisa de castigar civilizadamente había determinado una instancia diferente en la historia de las prisiones en Argentina. Como nuevo punto de partida en la reforma del castigo, los lenguajes de la ciencia encontrarían un derrotero eficaz para su desarrollo en la Penitenciaría Nacional, que se terminaría de fundir mejor hacia los primeros años del 900 con el desarrollo de la criminología local - proceso fortalecido por cátedras específicas y revistas ${ }^{-7}$. Sin embargo, esta situación no delimitó un factor común que se pueda extender fuera de Buenos Aires: objetivamente, la Penitenciaría Nacional en los primeros años del siglo pasado era apenas una prisión entre más de sesenta instituciones distribuidas a lo largo y a lo ancho del territorio argentino. Fuera de la ciudad porteña, recientes investigaciones revelan un paisaje variopinto en donde se imponen casos con trazos muy distantes en presupuestos, infraestructuras y expectativas con respecto el penal capitalino ${ }^{8}$.

9 Para estos años comenzaba a desarrollarse dentro del edificio un campo de saberes vinculados a aquellos impulsos de la criminología, que tuvo un lugar hegemónico en Europa durante gran parte del siglo XIX y la primera mitad del XX. La nueva ciencia generó no solo una innovadora forma de conocer el problema de la delincuencia en una 
sociedad -como Argentina- que crecía exponencialmente, sino también la emergencia de espacios de intercambios científicos que fueron parte del lugar común de varias trayectorias institucionales argentinas. Tal es el caso del Instituto de Criminología, establecido en 1907 bajo la dirección de José Ingenieros: entre sus funciones, se encontraban el estudio sintomático de los penados y procesados que conformaban la población carcelaria de la Penitenciaría Nacional. Tan pretencioso como innovador -el Instituto de Criminología fue el primero en el mundo con esas características-, la puesta en marcha del proyecto criminológico local confirmó el lugar ocupado por Argentina entre las vanguardias punitivas ${ }^{9}$.

Pero vanguardistas también serán los proyectos de publicaciones periódicas argentinos. En 1898 se publica el primer número de Criminalogía Moderna, un proyecto editorial de amplísima difusión tanto local como internacionalmente ${ }^{10}$. Su director, Pietro Gori, consolidó en poco tiempo una mirada local que sintetizaba aquella matriz positivista nacida en Italia, imponiendo una metodología y observación sobre el fenómeno de la criminalidad que priorizaba los caracteres de una sociedad viva por sobre lineamientos teóricos ortodoxos ${ }^{11}$. La publicación fue más intensa que extensa: para 1901, aparecía el último número debido a la escasez de fondos para solventar la publicación ${ }^{12}$. Si bien existió un número importante de textos en la revista que indagaron en la cuestión penitenciaria, uno de los puntos más referenciales al respecto estuvo centrado en la sección Estudios Carcelarios, que entre abril y junio de 1899 narró las percepciones de Gori y Juan Vucetich acerca de la prisión de Sierra Chica. La metodología adoptada para trazar el relato va más allá de las lecturas teóricas recurriendo a un gran abanico de recursos observacionales sobre los cuerpos vivos, como entrevistas, fotografías, y observación participante ${ }^{13}$.

11 Entre los principales colaboradores locales de la revista dirigida por Gori se encontraba un joven Ingenieros ensayando sus primeras armas en las letras científicas del saber criminológico ${ }^{14}$, quien, en 1902, apenas algunos pocos meses luego de la edición del último número de Criminalogía Moderna, fundaría Archivos de Criminalogía, Medicina Legal y Psiquiatría. Pero la presencia de las prisiones en las revistas no cobrará centralidad de manera constante y continua. A diferencia de otros campos de saber vinculados al crimen y al castigo, que tuvieron una presencia sostenida en publicaciones afines, las prisiones no contaron con una revista dedicada a los derroteros intelectuales que la administración penitenciaria en otras partes del mundo comenzaba a evidenciar. En tal sentido, la primera revista que se dedicó objetivamente a la cuestión fue la Revista Penitenciaria, dirigida por José Luis Duffy entre los años 1905 y 1909 como órgano oficial de la Cárcel de Encausados. En el programa, anunciaba su director:

Podría decirse que el conocimiento de las cuestiones relativas a los delincuentes y a la organización carcelaria, todavía se halla en embrión entre nosotros. Siendo así, es necesario dedicarse al examen de esos problemas, para contribuir al adelanto de la sociología criminal y de la ciencia penitenciaria. Reflejar en todas sus faces el movimiento de la Cárcel y llenar, o mejor dicho iniciar el programa que ha sido trazado, es el fin que se propone la Dirección, al publicar la Revista Penitenciaria ${ }^{15}$.

En este contexto encontraron cauces exitosos numerosas trayectorias, forjadas al calor de un saber fortalecido en dispositivos teóricos e instituciones físicas como la Penitenciaría Nacional. Quizá la más relevante de aquellas trayectorias para el periodo fue la de José Ingenieros, quien participó activamente en las páginas de la revista de Gori. La desaparición de Criminalogía Moderna generó un espacio de vacancia bastante breve, pero sintetizó un punto de partida intelectual y empírico para los expertos hacia el cambio de 
siglo donde las revistas se enmarcaban como una clara vidriera de las pretensiones de expertos del novecientos, impulsados por una mirada plantada en la intersección de la ideología y el saber docto.

Los Archivos de Criminalogía, Medicina Legal y Psiquiatría (en adelante, Archivos) aparecieron en $1902^{16}$. La publicación bimestral superó en calidad y cantidad cualquier otra publicación previa: solo el tomo correspondiente al primer año ascendía a más de setecientas páginas, que al igual que Criminalogía Moderna incorporaba colaboraciones de los principales referentes a nivel mundial. Los Archivos serán uno de los elementos de mayor proyección de la emergente criminología local, aunque con una intermitente presencia de la gestión de las prisiones durante los primeros años ${ }^{17}$.

En consonancia con las publicaciones mencionadas, las cátedras universitarias comenzaban a dar cuenta de la capacidad interpretativa de la criminología para el diagnóstico de los problemas sociales metropolitanos. Existe un consenso al considerar que la Facultad de Derecho y Ciencias Sociales de la Universidad de Buenos Aires fue pionera en la enseñanza de la doctrina positivista, donde por vez primera Norberto Piñero pensó un programa para la enseñanza del derecho penal con una fuerte presencia de las argumentaciones italianas privilegiando ideas como la pena indeterminada y la concentración de los procesos legales hacia las características del criminal en lugar del delito cometido ${ }^{18}$.

Desde los claustros emergería la figura de Eusebio Gómez, que rápidamente captó la atención de Ingenieros. Gómez comenzaría a definir los primeros trazos de una trayectoria sumamente fructífera, consolidándose como una figura de referencia en los dos temas sobre los cuales sostuvo sus principales actividades. Formado como abogado en la Facultad de Derecho y Ciencias Sociales de la Universidad de Buenos Aires durante los últimos años del siglo XIX, defendió su tesis doctoral apenas concluido su trayecto de grado con la tesis Sugestión y responsabilidad criminal en $1902^{19}$. Mientras se dedicaba al ejercicio del trabajo que su título lo habilitaba, escribió sus primeros textos de divulgación para un diario de la provincia de Mendoza acerca de - a su juicio - las principales prisiones del país. Estos textos fueron recopilados posteriormente en una compilación bajo el título de Estudios Penitenciarios, que vio la luz en 1906 prologado por el director de la Penitenciaría Nacional, Antonio Ballvé.

En aquel libro, Gómez afirmaba la necesidad de implementar un tratamiento penitenciario sostenido en la regeneración por medio del trabajo, una idea que ya circulaba en los congresos internacionales acerca de la materia. El penalista sostenía enfáticamente aquellas perspectivas que consolidaron a la Penitenciaría Nacional de Buenos Aires como un faro modernizador en el tratamiento punitivo del país, imagen que el mismo Ballvé se encargó de resaltar en varias ocasiones. En contraste, las perspectivas en torno a la prisión de Sierra Chica eran las más controvertidas y angustiantes por parte del observador, a partir de las cuales pretendía demostrar la distancia de los elementos que formaban el castigo moderno para el Centenario argentino:

(...) Gautier estaba en lo cierto al decir que la cárcel (...) es una verdadera cloaca que derrama en la sociedad una corriente, foco permanente de purulencias y de gérmenes contagiosos, fisiológica y moralmente, que emponzoña, embrutece, deprime y corrompe. Estas observaciones se nos ocurren al visitar Sierra Chica ${ }^{20}$.

En las ciudades centrales, el modelo de prisión-laboratorio que pretendía imponer la consagrada elite científica local convivía con la prisión-fábrica forjada por los directores 
de las prisiones, al calor de la cotidianidad y el día a día en la Penitenciaría. En este sentido, como bien demostró Lila Caimari, las tecnologías criminológicas de punta se insertaron en edificios muchas veces derruidos y anticuados, revelando la convivencia de dos modelos institucionales en una interrelación no ajena a las tensiones, pero que permitía la mutua existencia en paralelo de ambas propuestas. En este contexto se formará toda una generación de expertos en la cuestión criminal, con mayor o menor consciencia de las diversas expectativas respecto al castigo en la Penitenciaría Nacional. En este sentido, el Instituto de Criminología fue uno de los puntos determinantes en el trayecto formativo de Gómez, formando parte de este desde sus primeros días. Los Archivos se volverán la publicación oficial inmediatamente a su fundación, consolidándose como un importante dispositivo de experimentación sobre la población penada: "el Instituto de Criminología no tiene funciones jurídicas, sino puramente científicas. Es un laboratorio y una clínica", sintetizaba un entusiasta Ingenieros en un folleto de 1911. Por aquel año, trabajaban en su interior o colaboraban en la locación Horacio Areco, Francisco de Veyga y Helvio Fernández (sucesor de Ingenieros en la dirección del Instituto a partir de 1912). El Instituto de Criminología se convirtió rápidamente en una cantera prácticamente inagotable de sujetos pasibles de ser investigados. Conversaciones realizadas con la población penitenciaría le permitieron a Gómez escribir varios textos, pero el más importante de ellos fue sin duda La mala vida en Buenos Aires (1908), prologado por el mismo Ingenieros. La mala vida será el libro que ancló a Gómez a un periodo, un objeto de estudio y una metodología de análisis particular por las investigaciones de los últimos años ${ }^{21}$. En palabras de Salvatore:

(...) interesa a Gómez agrupar a un conjunto de prácticas y "malvivientes" -algunos delincuentes, otros no- que compartían tal vez un único elemento en común: habían aprendido a vivir sin trabajar por un salario. La mala vida es, en cierta medida, la contracara de la cultura del trabajo, una subcultura delincuencial cuya reproducción obstaculiza el funcionamiento de la empresa capitalista y los mercados de trabajo, además de amenazar la propiedad de los habitantes de las metrópolis ${ }^{22}$.

19 El primer capítulo de La mala vida será incluido de manera íntegra entre las páginas de los Archivos, marcando el inicio de una fructífera colaboración tanto con la revista como con el instituto ${ }^{23}$. Estas primeras contribuciones de Gómez en los Archivos son representativas de este momento de intensa y comprometida reflexión acerca de las prisiones argentinas de Gómez. El trabajo carcelario fue un texto focalizado en la capacidad regeneradora de la labor de los penados, aunque centrado en la Penitenciaría Nacional. Al respecto, sostenía Gómez que "[e]l trabajo, regularizando las funciones de la vida psíquica y orgánica del penado, constituye el agente moralizador más importante á que se pueda recurrir en esa lucha inteligente y razonada en que los pueblos civilizados se empeñan contra el delito" ${ }^{24}$.

La aparición de Criminología Argentina (1912) ayudó a consolidar un proceso iniciado durante los últimos años del siglo XIX: demostrar la conformación de una criminología de raíces locales, centrada en objetos de estudios concretos $^{25}$. El amplísimo fichaje bibliográfico de Gómez estuvo antecedido del texto El problema penal argentino, que había aparecido primero entre las páginas de los Archivos ${ }^{26}$. La hipótesis de Gómez es que la capacidad punitiva de un estado tiene una naturaleza cambiante, que reconoce en la misma sociedad sus modalidades represivas, los crímenes que deben ser reprimidos. Esta concepción, presente en gran parte del positivismo penal, se distancia de la idea de que la pena es un ente abstracto, por lo cual no debe ser un recurso preventivo para la sociedad ${ }^{27}$. Sin embargo, la utilidad del artículo reside en la descripción, detallada y precisa, del 
sistema penal y penitenciario argentino -aunque con aseveraciones que pueden llegar a ser consideradas algo entusiastas.

21 El problema penal en Gómez tiene varias raíces, que pueden resumirse en algunos puntos esenciales; a saber:

a) La falta de estadísticas a nivel nacional;

b) El progresivo aumento de la delincuencia precoz en menores;

c) La constante y creciente urbanización de la ciudad de Buenos Aires;

d) La incapacidad de la sociedad argentina de hacer cumplir el derecho penal;

e) La deficiencia, material y organizativa, del régimen penitenciario argentino.

Más allá de las discusiones trazadas al respecto, no puede negarse que Gómez conocía y dominaba este campo de estudios: además de la formación en derecho y el enorme esfuerzo en la escritura de sus obras, el intenso desarrollo de su trayectoria intelectual por estos años también se explica por el amplio abanico de relaciones sociales constituido durante estos años, entre quienes se destacan Ingenieros y Ballvé. El Instituto de Criminología será uno de los dispositivos más importantes en sus narrativas, que le permitió tener un contacto constante con la población penada alojada en los pabellones de la Penitenciaría Nacional.

Probablemente, Gómez se haya distanciado del Instituto de Criminología unos pocos meses después de la renuncia de su director y fundador, pero no sin antes llevar adelante el evento más representativo en la cuestión penitenciaria del periodo. Para 1914 el Instituto de Criminología, ya bajo la dirección de Helvio Fernández, organizó un Congreso Penitenciario Nacional para reunir a médicos, penalistas, expertos, directores de prisiones y demás personas vinculadas a la gestión de las prisiones argentinas; del cual Gómez será uno de los principales organizadores ${ }^{28}$. Bajo explícito encargo de la Comisión del Congreso, se le encomendó a Gómez la realización de una Memoria Descriptiva de la Penitenciaría Nacional, en un volumen impreso en alta calidad en los Talleres Gráficos de la Penitenciaría Nacional y editada por el Instituto de Criminología. El Congreso Penitenciario Nacional sentaría un precedente importantísimo en las discusiones expertas y administrativas, evidenciando la preocupación local por mejorar la gestión de las prisiones argentinas ${ }^{29}$. Lamentablemente, la experiencia no volverá a repetirse hasta la década de 1940, con el Congreso Penitenciario Justicialista. En este sentido, la falta de interés institucional en la organización de un evento se sumaría a un conjunto de cuestiones que favorecerían la concepción de la administración penitenciaría como un saber práctico, construido más cerca de la cotidianeidad de los establecimientos que de las cátedras universitarias, las tesis, los congresos científicos y los grupos de investigación.

Luego del Congreso, Gómez se dedicará principalmente al ejercicio de la abogacía, siendo extrañas las publicaciones del tema penitenciario durante lo que quedaba de la década. Retomando las vetas sociológicas y etnográficas que habían caracterizado la escritura de La mala vida, edita en 1917 el libro Pasión y delito. Aquel mismo año, habiéndose augurado la reforma del Código Penal vigente, publicó algunas reflexiones sobre este mismo en forma de artículos, aparecidos en las principales publicaciones porteñas dedicadas a la materia.

El cambio de década trajo consigo la inauguración de un periodo bastante provechoso para el abogado rosarino, que apenas pasaba los cuarenta años. En 1921 comenzó su trayectoria docente dentro de la Facultad de Derecho, primero como adscripto a la 
cátedra de Juan P. Ramos, y luego como profesor titular tras la apertura de una segunda cátedra de Derecho Penal ${ }^{30}$. Hasta 1946, el penalista y penitenciarista se mantuvo al frente de su cátedra, por la cual pasaron docentes como José Peco, Jorge Eduardo Coll, José María Paz Anchorena y Emilio Díaz, entre otros.

La conformación de grupos de investigación, como han notado Zimmermann y Plotkin, fueron un elemento importante para la conformación de un saber estatal. En esta misma tónica, se podría mencionar la conformación del Centro de Estudios Penales (en adelante, CEP), que se sumaba a una cantidad no despreciable de agrupaciones interesadas en la difusión de saberes penales vinculados a la criminología y el derecho penal. El CEP funcionó entre 1922 y 1928, periodo en el cual también editó la Revista Penal Argentina. Entre sus páginas, aparecerían las primeras notas de jurisprudencia desprendidas del nuevo Código Penal argentino, sancionado poco tiempo antes del primer número de la Revista $^{31}$. El CEP, que inicialmente estuvo conformado por los profesores de la cátedra de Derecho Penal de la UBA, fue un espacio importante de intervención y en la proyección de reformas del sistema punitivo del gobierno radical de Marcelo T. de Alvear ${ }^{32}$. Durante los años en los que el Centro tuvo labor activa, merecen prestar atención a la inmensa cantidad de jurisprudencia discutida en la Revista Penal Argentina, los sucesivos proyectos de estado peligroso - que proponían el establecimiento de la pena pre delictual - y la organización del segundo censo carcelario a nivel nacional ${ }^{33}$.

En resumen, la importancia de las revistas en este primer periodo de la trayectoria institucional e intelectual de Gómez es muy considerable, teniendo en cuenta la amplísima difusión que tenían estos proyectos editoriales. Por otra parte, es notable ver como durante las primeras décadas del siglo XX, no existió un proyecto de revista que priorice las cuestiones penitenciarias. En este sentido, los trabajos que indagaron en la administración de las prisiones fueron incorporados a publicaciones más amplias, regidas por el amplísimo paraguas intelectual que representaba la criminología, ya sea a finales del siglo XIX (como fue el caso de Criminalogía Moderna) o en las primeras décadas del siglo XX (cuando comenzó a publicarse Archivos) Una notable excepción fue la Revista Penitenciaria dirigida por Duffy. Parte de esta vacancia será saldada, aunque brevemente, con el BBNCCA dirigido por Gómez durante la siguiente década.

En segundo lugar, la atracción provocada por la Penitenciaría Nacional explica la paulatina incorporación de textos acerca de la cuestión penitenciaria en la revista dirigida por Ingenieros: la conformación del Instituto de Criminología en la locación de la prisión porteña representó también un acceso privilegiado a muchos médicos, abogados, y expertos en general devenidos en criminólogos a una constante disponibilidad de cuerpos penados pasibles de ser observados.

\section{Características generales del BBNCCA. La enciclopedia viva de las prisiones}

Le bulletin de la Bibliothèque du Penitencière de Buenos Aires, promet, comme on voit de devenir sous la puissante direction de M. Gómez, une encyclopédie vivante et la première source d'information du monde pour les fonctionnaires et employés des prisons ${ }^{34}$.

La idea de una publicación en forma de boletín supone el compromiso de transmitir un resumen de las actividades emprendidas por una institución de manera periódica, definición que toma algo de distancia del género revista en cuanto a la presencia de ideas, 
discusiones y puntos de vista. Aún así, la publicación dirigida por Gómez presenta un sesgo muy interesante en la presentación y selección de informaciones a transmitir, además de un conjunto de textos publicados por él mismo que revelan la ideología del penalista, compartida en gran parte por varios de los expertos nucleados en Buenos Aires. La publicación no contó, ni en el primer número ni en ninguno de los siguientes, con un editorial o nota introductoria sintetizando sus alcances. La única referencia que puede encontrarse acerca de las expectativas de la publicación es el decreto autorizando su edición, que será transcripto en la contratapa de varios números del Boletín:

Vistos: la nota del señor Director de la Penitenciaría Nacional, doctor Eusebio Gómez, en la que propone las medidas conducentes a obtener que la sección de la Biblioteca del Penal que comprende las obras relacionadas con la especialidad de las funciones a que el Establecimiento está destinado, alcance el desarrollo necesario y, Considerando: que es de evidente conveniencia reunir en esta sección todas las obras de Criminología y ciencias afines, a objeto de facilitar al personal del Establecimiento la preparación que reclama el carácter técnico de las funciones que le incumben; Que esta misma medida permitiría a todos los empleados de cárceles como a los estudiantes de derecho que lo desearan, extender y completar sus conocimientos teóricos y de organización práctica de los servicios penitenciarios, donde tantas reformas se han introducido con motivo de las nuevas orientaciones de la penología, el Presidente de la Nación Argentina - Decreta: Art 1º, La Dirección de la Penitenciaría Nacional organizará la referida sección de la Biblioteca, que se denominará 'Biblioteca Nacional de Criminología y Ciencias Afines', a la que tendrán acceso los empleados de los establecimientos penitenciarios del país así como los estudiantes de derecho de las universidades nacionales, en la forma que disponga la reglamentación que dictará la Dirección de la Penitenciaría Nacional. Art $2^{\circ}$. Periódicamente se publicará un boletín en el que se anunciarán las últimas informaciones bibliográficas sobre la materia y se dará cuenta de las disposiciones legales y administrativas, nacionales y extranjeras, sobre asuntos penitenciarios. (... ) ALVEAR ${ }^{35}$.

Como bien ha notado Norberto Dagrossa en la redacción de su índice para el BBNCCA, la existencia de una biblioteca de criminología en la Penitenciaría Nacional parece no ser una novedad ${ }^{36}$. Si nos remitimos a un folleto editado por el Instituto de Criminología, ya funcionaba teóricamente desde 1907 una biblioteca dedicada a las cuestiones que estudiaba Archivos $^{37}$. Sin embargo, Osvaldo Loudet, en una nota escrita por él mismo afirma que la biblioteca recién comenzó a dar servicios adecuados en $1930^{38}$.

Lo que se sabe acerca del funcionamiento de la Biblioteca Nacional de Criminología y Ciencias Afines es muy poco: hacia el final del informe presentado para el año 1925, Gómez menciona que el trabajo en la biblioteca era realizado por personal del penal porteño. La labor realizada era la clasificación de la bibliografía por materia y por autor, tanto de libros como de artículos originales "insertos en revistas técnicas". En la misma nota, aclara el director que uno de los puntos más importantes del BBNCCA será la conformación bibliográfica: "se registrarán no sólo las obras y trabajos que existían en la Biblioteca, sino también, los de otras colecciones, a fin de formar una bibliografía criminológica, argentina y extranjera, lo más completa posible" ${ }^{39}$.

Más allá de toda esta cuestión acerca de la novedad (o no) de la biblioteca, el BBNCCA era una realidad, y publicó entre julio de 1926 y enero de 1929 un total de once números, compilados en dos tomos de cuatro números y un último tomo con las últimas tres ediciones publicadas antes de su interrupción. El motivo aparente del fin de la publicación lo adjudicamos al cese de las actividades de Gómez como director de la Penitenciaría Nacional en octubre de 1928, tras ser públicos los resultados de las 
elecciones nacionales que llevaron a un segundo mandato a Hipólito Irigoyen ${ }^{40}$. El último número del boletín aparece en enero de 1929, sin contar con el nombre de Eusebio Gómez en la portada como en todas las anteriores: esta edición se caracteriza por ser la menos abultada de todas las publicadas, y no incluye ningún mensaje respecto a la finalización.

Cuantitativamente, el boletín se publicó con una cifra aproximada de cien páginas por número trimestral. Lamentablemente desconocemos tanto el tiraje como el precio de venta, ya que no se encuentran impresos en ninguna de las tapas disponibles en los repositorios consultados ni se hace mención alguna en los correspondientes informes presentados al Ministerio de Justicia; aunque sí sabemos que los fondos para la impresión formaban parte de las partidas generales anuales de la Penitenciaría Nacional ${ }^{41}$. Como gran parte de las publicaciones periódicas de la época, el sistema de "canje" permitía tomar contacto con un importante número de proyectos editoriales, tanto locales como del exterior. Al funcionar la Biblioteca que daba sentido al boletín en la Penitenciaría Nacional, la locación a la que se debían remitir los envíos era la misma de la prisión porteña. Su horario de funcionamiento: de 12 a 16, mediante previa autorización del director del establecimiento.

El enfoque del BBNCCA será sumamente institucional, recuperando en gran parte de sus secciones textos que fueron presentados con otros motivos y en diferentes lugares, como memorias (tales son los casos de los informes acerca de la Penitenciaría Nacional, presentados anualmente al Ministerio de Justicia e Instrucción Pública, y las memorias del Patronato de Liberados, que eran publicados en forma de folleto por fuera del Boletín, entre otros ejemplos) o las leyes y proyectos legislativos presentados en la Cámara de Diputados. Esto da cuenta del carácter informativo del boletín, que pretendía mantener una actualización constante acerca de las decisiones estatales en la cuestión penal y penitenciaria. Sin el mismo nivel de detalle, pero con un importante número de notas al respecto, fueron incorporados similares referencias provenientes del mundo entero, revelando el interés de conocer los regímenes extranjeros y las condiciones de las prisiones e instituciones de castigo en una escala más amplia. Como veremos más adelante, la dimensión internacional de la revista será una variable constante, formando parte del carácter de la publicación a lo largo de todas sus secciones.

Las secciones del BBNCCA serán, en varios aspectos, una demostración de la erudición del director del boletín en las temáticas criminológicas "y afines": el centenar de publicaciones reseñadas en la sección "Bibliografía" sorprende más por su cantidad que por su calidad, evocando en pocos párrafos el sentido de los textos. A diferencia de otras secciones, tanto autores locales como extranjeros son reseñados sin discriminar su pertenencia geográfica, aunque es notoria la presencia europea. La veta bibliotecológica demostrada en Criminología Argentina estuvo presente en la selección bibliográfica del BBNCCA: las reseñas estarán organizadas bajo gran cantidad de secciones como Derecho Penal, Sociología, Medicina Legal, etc. Inferimos, por la ausencia de autores, que las reseñas eran escritas por Gómez ${ }^{42}$. La profundidad de los análisis bibliográficos probablemente esté sujeta a una variable subjetiva, que explicaría extensiones de dos o tres carillas para algunos textos a unas pocas líneas para otros escritos recibidos por la dirección ${ }^{43}$.

La sección Doctrina no presentará muchas novedades con respecto a otras publicaciones similares, donde aparecían trabajos monográficos; aunque podemos mencionar que llama la atención la gran cantidad de textos traducidos - casi sin lugar a dudas por el mismo Gómez -. Los textos a menudo mencionan las fuentes de donde fueron extraídos: diarios, 
revistas nacionales o extranjeras, artículos. En varias oportunidades, la voz institucional de Gómez se desdobla a través de notas al pié, donde confronta con otros autores o aclara algunas cuestiones con respecto a la traducción bajo seudónimos como "La Dirección" o "La Redacción": un ejemplo oportuno es la nota al pié hacia el final de un texto de Enrique Ciaccio acerca de un curso de disciplina carcelaria dictado en Roma, donde el director del BBNCCA expresó que sus conclusiones eran inaceptables. Como característica constante, se mantendrá la brevedad de los escritos, superando pocas veces las cinco carillas, agilizando muchísimo la lectura de la publicación y demostrando la función informativa que Gómez pretendió imprimir al boletín.

A través de otras secciones importantes como Crónica, se publicaban informaciones acerca de las prisiones del país y del mundo que pretendían dotar de la publicación periódica de un carácter actualizado. Reuniones, congresos, y conformación de instituciones a lo largo del mundo convivieron con traducciones a diversos idiomas de textos de autores argentinos como José María Paz Anchorena. La internacionalización de la sección, aunque centrada principalmente en Italia, fue muy importante: a través del boletín, los lectores tuvieron noticias acerca de revistas para penados en Cuba, la convocatoria al premio Cesare Lombroso, y diversas modificaciones y estudios acerca de las codificaciones penales del mundo entero en brevísimos párrafos. Captó singular atención la reforma penal italiana, tema sobre el cual Gómez escribió varios textos que luego fueron recopilados en un libro posterior ${ }^{44}$.

40 La sección "Crónica" estaba presente en varias publicaciones de la época (como la Revista Penal Argentina), y será retomada luego por la Revista Penal y Penitenciaría ${ }^{45}$. De la misma manera, la revista Dirección General de Estudios Penales contó con otra sección similar a "Administración y régimen de las penas", que también vio la luz desde los primeros números del boletín. Las notas acerca de la administración de las prisiones incorporaban documentaciones provenientes de las principales naciones europeas que fueron las referencias permanentes en la obra intelectual de Gómez, pero también aparecían menciones a lugares muchísimo más remotos para los expertos argentinos, como Polonia, Lovaina, China o Egipto. Aunque no hubo distinción entre los textos acerca de países extranjeros y los escritos locales (como si estuvo presente en otras secciones de la publicación), prevalece una mirada un poco más amplia acerca de la situación penitenciaria nacional que aquella focalización en Buenos Aires esbozada por Gómez a principios de siglo. De todas maneras, este foco más amplio solo se extendió hacia Córdoba y Tierra del Fuego, y aún así debe ser tomado con reservas. Los informes publicados formaban parte de las tareas desarrolladas por la Comisión de Superintendencia de Cárceles, que se había conformado en 1925 y sus funciones coincidieron con los años en que el BBNCCA fue publicado.

41 Contaron con una distinción local/extranjera otras dos secciones del BBNCCA. La sección "Leyes y proyectos legislativos", una de las más extensas en cuanto a contenido publicado, indagó en varias leyes y proyectos de reforma. En la sección local, fueron reproducidos los textos en su totalidad, entre ellos la propuesta de la introducción del estado peligroso en el Código Penal, varios proyectos para colonias y hogares para menores abandonados, y los reglamentos de la Cárcel Penitenciaria de Tucumán y el Instituto Correccional de Mujeres de Santa Fe. En el primer número son transcriptas tal cual fueron presentados en la Cámara de Diputados los proyectos de la Comisión Especial de Legislación Penal y Carcelaria. 

"Índices bibliográficos", que tuvo una presencia permanente debido a la publicación en su totalidad del repertorio bibliográfico del Instituto de Medicina Legal de París, repartido por partes alfabéticas a lo largo de casi todos los números. Aparecieron, esporádicamente, listados de bibliografías individuales como Luís Jiménez de Asúa, Quintiliano Saldaña, Manuel Carnevale, Silvio Longhi y Enrico Pessina. La única mención local fue para un índice de artículos doctrinarios de la Revista Penal Argentina, que también se interrumpiría en 1928. Algunas secciones, como "Prisiones Históricas", solo aparecieron una vez ${ }^{46}$. institución se encontraba totalmente resquebrajada frente a la opinión pública. En plena intervención del Ministerio de Justicia por irregularidades durante la gestión de Nicolás Menéndez, la fuga grupal de 1923 concluyó con la posibilidad de un reordenamiento posible ${ }^{47}$. Sin embargo, tal como sostuvo Rodolfo Moreno acerca de las evasiones de las prisiones, los hechos se olvidan rápidamente y la ineficacia de las autoridades en capturar a los escapistas se traduce en un éxito de estos mismos ${ }^{48}$.

Pero para 1925, la Penitenciaría Nacional era vuelta a presentar al mundo nuevamente como un modelo de castigo moderno, aunque al poco tiempo los cuestionamientos volverían $^{49}$. Los fuertes trazos disciplinarios ya habían comenzado a concretarse con la implementación del traje a rayas, una medida que iba en creciente descrédito en las discusiones internacionales. Sostenía Gómez al respecto:

La Dirección actual ha reaccionado contra el sentimentalismo romántico, que considera nocivo para los fines de la represión; y partiendo del principio de que la acción penitenciaria ha de tender, ineludiblemente, a sugerir reglas, orden y método en el modo de vivir, procura realizar esta sugestión valiéndose de todos los 
medios compatibles con un alto humanitarismo, pero sin excluir la coacción física inevitable ${ }^{50}$. cerca las iniciativas tomadas por Gómez en los últimos años a cargo de la dirección de la Penitenciaría Nacional. A partir de 1925, la prisión porteña ya contaba con un ligero número de reformas realizadas a partir de dos movimientos institucionales sumamente importantes para la historia de la institución. En primer lugar, durante aquel año se aprueba y pone en práctica el reglamento de la Penitenciaría Nacional. Pese a comenzar su edición en 1926, no encontramos en el BBNCCA la publicación del Reglamento de la Penitenciaría Nacional presentado el año anterior ${ }^{51}$. Ignoramos el motivo que llevó a tal omisión: el Reglamento de 1925 no solamente fue adoptado en los años posteriores por otras prisiones del país -como Tierra del Fuego-, sino que fue el primero que tuvo la institución porteña. Tal como señaló García Basalo, desde 1877 la Penitenciaría Nacional se rigió por un reglamento provisorio, que fue paulatinamente acrecentado mediante diversas órdenes del día. El reglamento redactado por Gómez incorporó por vez primera una sumatoria de apartados dedicados a los accidentes de trabajo ${ }^{52}$.

Con respecto al reglamento, sostenía Gómez que el mismo no respondía a ningún otro modelo penitenciario vigente. Negaba la influencia del sistema Auburn, porque "la regla del silencio durante el trabajo y en las diversas ocasiones en que los reclusos encuéntranse reunidos, que prescribe dicho sistema, es impracticable y cruel". Asimismo, consideraba que el sistema de reclusión celular absoluta era "contrario a la naturaleza humana". Descartaba también la inspiración de los modelos reformista y progresivo por no estar adecuados a la legislación penal argentina. Hacia referencia el director de la Penitenciaría Nacional que allí se llevaba adelante un "sistema argentino", sostenido en el trabajo y un disciplinamiento severo, regulada por un Tribunal de Conducta.

En segundo lugar, la punta de las intervenciones en clave industrializadora del régimen penitenciario pensado por Gómez comenzaría a definirse con la apertura de la Escuela de Electrotécnica, a la cual se le anexaría una sección de Galvanoplastía en 1926. El trabajo de la población penada era, en su imaginario, el punto más importante para la regeneración moral de los delincuentes, que completaba la tríada compartida con la instrucción obligatoria y la disciplina. Pero también la industrialización del trabajo en los talleres dinamizaba las labores diarias. Hacía muy poco tiempo, el director de la prisión argentina había viajado junto con una comisión designada por el Poder Ejecutivo a Londres, para presentar informes acerca del castigo en Argentina, exponiendo la importancia de considerar criterios de clasificación alternativos que prioricen las capacidades laborales por sobre los rasgos psicopatológicos ${ }^{53}$. 
52 En este sentido, los artículos que mejor reflejan el pensamiento penitenciario de Gómez tienen una presencia importante en el BBNCCA. Si bien no se tratan de escritos originales pensados para el boletín, su inclusión refleja una intención implícita de la publicación: establecer la centralidad del "régimen penitenciario argentino" dentro de su "enciclopedia viva" de los saberes penitenciarios, compuesta de una múltiple y variopinta cantidad de escritos acerca de la situación punitiva. La dimensión internacional estará presente en las administraciones estatales posteriores, reflejada en publicaciones como la Revista Penal y Penitenciaria. Durante todos los años en que el BBNCCA fue publicado, aparecieron oportunamente entre sus páginas los informes enviados al Ministerio de Justicia anualmente, más no los cuadros estadísticos y tablas.

El Cincuentenario de la Penitenciaría Nacional fue uno de los momentos mejor capitalizados por Gómez a través de la revista con un doble objetivo: por un lado, permitió consolidar su figura ya no como un experto formado en las cátedras - como se lo había cuestionado a Ramos luego de los polémicos sucesos acaecidos durante la intervención de 1923 - sino como parte de la burocracia institucional en su rol primero como director y luego también como parte de la Comisión de Superintendencia de Cárceles; y por otro lado sintetizó sus ideas penitenciarias a través de una gestión que institucionalmente podría tildarse de exitosa.

54 Son escasas las menciones en relación con la instrucción en las prisiones, que fue uno de los puntos más proyectados en la Penitenciaría Nacional durante la década del veinte. La ampliación de la formación educativa se extendería hacia dos direcciones distintas: por un lado, la instrucción de la población penada, recuperando el impulso de la enseñanza en tiempos de Ballvé. Pero, por otro lado, el imperativo también se extendería al personal subalterno. Una Escuela de Celadores y Guardiacárceles fue pensada para 1924, como respuesta tanto a la demostrada complicidad de los empleados con algunos de los fugados, pero también como paliativo a la escasa formación del personal. Sostenía Gómez que:

En la actualidad, y a pesar de todas las precauciones con que esta Dirección procede

al designar las personas que han de ocupar los cargos de celadores y guardianes; a pesar de las garantías que, para esas designaciones exige, el personal de la referencia carece, en su mayoría - por no decir en su totalidad - de una noción clara y precisa de las funciones que le competen ${ }^{54}$.

55 La Escuela de Celadores y Guardianes contemplaría aceptar a alumnos externos del edificio, siempre y cuando no sobrepasen la cuarta parte del personal efectivo de la Penitenciaría. Aún así, para ser aspirante los requisitos no eran excluyentes (ser argentino nativo o naturalizado, de entre 22 y 35 años, saber leer y escribir, manejar las cuatro operaciones aritméticas, tener "buena salud y buena constitución física", y los papeles administrativos correspondientes). Con gran empeño, Gómez pensó el programa de contenidos para la escuela que, aunque sumamente sintético, presentaba sutiles diferencias entre los contenidos correspondientes a celadores y guardianes en las materias gramática, geometría y aritmética; pero era el mismo para el resto de las asignaturas $^{55}$.

Por otra parte, la Escuela de Penados impartía un plan de estudios similar al de instrucción primaria en las escuelas, pero con ciertas modificaciones. Existía cierto consenso en pensar que la escolarización de la población penada no debía limitarse en la mera alfabetización, ya que "se ha pensado que esas condiciones requieren una selección particular de materias que, desarrolladas convenientemente, obren sobre la inteligencia y la conciencia moral del preso de un modo más directo que la escuela primaria del niño" ${ }^{56}$. 
57 Las materias dictadas eran, para el primer año: lectura y escritura, idioma nacional, moral, historia. Para el segundo, aritmética, geografía, ciencias físicas y naturales. Para el tercer y último año: caligrafía, dibujo artístico e industrial, jardinería y horticultura, escritura a máquina y contabilidad, evidenciando el carácter centrado en los oficios.

En el BBNCCA es persistente el dato del director con respecto a la curva ascendente que cobraba la producción del trabajo de los penados, ascendiendo su pico máximo en 1926 con $\$ 1.587 .696,94 \mathrm{~m} / \mathrm{n}$ - lo que representaba un 63 por ciento del presupuesto general de gastos de la institución ${ }^{57}$. El dato se reitera a lo largo de los tomos del boletín, ya que ese beneficio era el que permitía comprar nuevas maquinarias y emprender las refacciones necesarias para maximizar la productividad de los talleres de penados. Las reformas realizadas al taller de Carpintería permitían construir y entregar cien bancos diariamente para los institutos docentes nacionales, mientras se confeccionaban las seis mil urnas electorales requeridas por el Ministerio del Interior para las elecciones nacionales.

La síntesis de las acciones llevadas adelante por la gestión de Gómez se encuentra en un oportuno escrito publicado en el BBNCCA:

Creación de la Escuela-taller de Electrotécnica (...);

Instalación de un taller de electricidad, que, bajo la dirección de un maestro, atiende el servicio complejo de luz y fuerza motriz de todo el establecimiento (...);

Instalación de cuatro telares a mano; ensayo de la confección de medias para uso de la población penal;

Instalación de un taller especial para la fabricación de bancos escolares (...);

Creación, sobre la base de los elementos ya existentes, del taller-escuela de Jardinería y Floricultura y la Escuela de Horticultura ${ }^{58}$.

60 La creación de los nuevos talleres implicaba enseñar a los penados los oficios necesarios para producir los objetos en la calidad ofrecida por la industria privada; mientras que el mejoramiento de los talleres ya existentes perseguía un motivo instructivo para los penados, ayudando a estos a alcanzar las enseñanzas en un oficio necesarias para el emprendimiento una vez que estén en libertad. En este sentido, se adecuaron los talleres ya existentes (taller de cocina, peluquería, taller de zapatería, taller de panadería, taller de fideería, taller de fotografía, taller de fotograbado, taller de imprenta de obras, taller de encuadernación, taller de imprenta de boletines, taller de lavadero, taller de carpintería, taller de herrería, taller de mecánica, taller de fundición, taller de albañilería). Entre las “modernizaciones" introducidas, se mencionan adquisiciones de maquinarias, contrataciones de capacitadores, y reacondicionamiento de locales, además de la reparación de maquinarias en desuso ${ }^{59}$.

61 Así como la síntesis descripta anteriormente, las acciones de los últimos años de Gómez al frente de la Penitenciaría Nacional encontraron un cauce propicio en las páginas del BBNCCA, persiguiendo la pretensión de dotar de una envergadura pragmática a la gestión de la prisión modelo. Por eso mismo, consideramos que el evento que mayores atenciones cautivó fue la celebración del Cincuentenario de la Penitenciaría Nacional, que fue una clara muestra de los alcances del trabajo llevado adelante por los penados.

De todas maneras, consideramos que la celebración del Cincuentenario de la Penitenciaría Nacional fue un evento más relevante para la burocracia penitenciaria que para la población penada que pasaba sus días y sus noches en las celdas de la prisión porteña. Decimos esto por varios motivos, que desarrollaremos brevemente a continuación: en primer lugar, la locación seleccionada para realizar el evento; en segundo lugar, por las 
características de los discursos y, en tercer lugar, la demostración de los vínculos de Gómez con miembros de la sociedad industrial del periodo, que no son sociales y económicos únicamente sino también políticos.

El BBNCCA da cuenta de la organización de las celebraciones, que no tuvo lugar en la Penitenciaría Nacional como habría de suponerse: Gómez no presenta ninguna explicación acerca de esta decisión, ni tampoco expone indicios de por qué el evento se llevó a cabo en el Salón de la Unión Industrial Argentina (UIA). El Salón, que iba a ser inaugurado para el evento, estaba ubicado en Avenida de Mayo al 115760: allí se daría lugar, simultáneamente, la Exposición Industrial Argentina.

El número 5 del BBNCCA comienza con la completa transcripción de los discursos presentados el día del evento, siendo los oradores el ministro de justicia Antonio Sagarna y obviamente el director de la Penitenciaría Nacional, Eusebio Gómez. No nos sorprende encontrarnos con que el centro de ambos discursos sea el trabajo en las prisiones y la guerra a la "vagancia". En palabras de Sagarna, "[l]a Penitenciaría, que ha suprimido la ociosidad, las caras torvas del presidiario de novela, que ha suprimido hasta el famoso olor a preso tan característico, no ha suprimido la esperanza en ningún corazón recluido" 61 .

Sagarna enfatizó frente a un salón repleto la cercanía entre la UIA y los talleres de la Penitenciaría Nacional, cuyo vínculo histórico había comenzado en 1878 cuando el primer director, Enrique O' Gorman, había solicitado al gobierno porteño que se den preferencia a los tejidos de producción nacional ${ }^{62}$. Sostenía el ministro de Justicia:

El trabajo, como la ley de la vida, como habilitación para responder a los fines subsidiarios de la pena, como norma e instrumento disciplinario, como precepto higiénico y como instrumento y vehículo de la efectiva reforma y mejora integral del penado, ha sido el núcleo central del programa planteado y desarrollado en los últimos cuatro años en el régimen penitenciario de Buenos Aires $\mathrm{y}$, en especial, en el establecimiento cuyo 50.o aniversario conmemoramos con esta exhibición de sus resultados ${ }^{63}$.

Las capacidades regenerativas del trabajo fueron expresadas aún con mayor vehemencia por Gómez, quien sostuvo que la falta del hábito del trabajo muchas veces forzó a quienes estaban penados a transgredir "las normas de la convivencia social" ${ }^{64}$. Para el director existen dos obligaciones irrenunciables dentro de la población penal: por un lado, la del trabajo (tal como sostiene el Código Penal), por otra, la indemnización a las víctimas. Las mejoras en la organización industrial serían, en el discurso de Gómez, una acción benéfica que mediante la primera alcanzaría la segunda.

67 Conforme a los criterios y escasos consensos alrededor del trabajo, sostenía el director que la labor carcelaria debía responder a un "objeto educativo e higiénico, de habilidad técnica y rendimiento económico". Llama la atención Gómez acerca de los importantes costos que representa el mantenimiento de las prisiones para el estado argentino, aunque se reserva sus opiniones con respecto a la imposibilidad del resto de las instituciones punitivas a nivel nacional, para las cuales mantener activos sus talleres resultaba dificultoso o incluso imposible. En Buenos Aires, la Penitenciaría Nacional estaba a poco tiempo de alcanzar el mayor objetivo de Gómez: producir en los talleres la cantidad necesaria para lograr solventarse por sus propios medios.

Por último, la organización del evento evidenciaba los estrechos vínculos de Gómez con las figuras del industrialismo argentino, que García Basalo relata en un notable artículo: Ernesto Tornquist y la familia Piccardo (ambos acreedores de la tabacalera argentina 
Piccardo y Cía., ya consolidada como una de las industrias más importantes del país), y los dirigentes de la Fábrica Argentina de Alpargatas S.A., la Compañía General de Fósforos, la Cervecería Quilmes y la empresa alimenticia Bagley aportaron importantes sumas, que ascendían a algo más de $\$ 12.000$ en total junto con otras colaboraciones en efectivo ${ }^{65}$.

El BBNCCA solo transcribe los discursos de Sagarna y Gómez, dejando de lado las voces de Luis Colombo (presidente de la UIA), Alvear, y Emilio Mihura (ministro de Agricultura). Las mismas transcripciones fueron publicadas en la Revista de Criminología, Psiquiatría y Medicina Legal. En la sección Crónica del BBNCCA, se publicó otro texto relativo al Cincuentenario, donde se destacan los alcances de la Penitenciaría Nacional para el año 1927.

70 Un singular catálogo de la exposición fue editado también para ilustrar el evento, con un notable trabajo gráfico que también evidencia los alcances técnicos que Gómez se encargó constantemente de hacer notar en los mensajes al Ministro de Justicia. A las 75 páginas que componen el documento, se anticipan las palabras que hubiera ofrecido Gómez en la inauguración de la exposición., tituladas como "La organización industrial de la Penitenciaría Nacional de Buenos Aires". En ellas, el director sintetiza cuales eran las características del régimen de trabajo, donde anticipa que las labores no tienden a convertirse en un "venganza expiatoria", respondiendo a los cuestionamientos -ya muy tempranamente instalados- de que la Penitenciaría Nacional se trataba de un "hotel de lujo para los más peligrosos criminales". Por esto mismo, el trabajo debía ser "obligatorio, educativo e higiénico, de habilidad técnica y rendimiento económico", incurriendo su evasión en una falta grave sobre la que se imponía una "severa disciplina" ${ }^{66}$.

\section{Conclusiones}

71 A lo largo de este trabajo hemos intentado demostrar la irregular presencia de la cuestión penitenciaria en las revistas argentinas durante los primeros años del siglo XX, pese a varios esfuerzos, los cuales fueron más individuales que colectivos. En este sentido, hemos atravesado el complejo corpus bibliográfico existente a partir de la figura de Eusebio Gómez, uno de los más importantes promotores de este tipo de saberes durante el periodo. Además de las pretensiones de expertos, la presencia de la Penitenciaría Nacional y el enorme poder de atracción que generó el Instituto de Criminología para los expertos del periodo fueron variables sumamente relevantes para el abordaje de la problemática: los estudios acerca de las prisiones no encontrarán un derrotero constante hasta 1933, cuando comience a editarse la Revista Penal y Penitenciaria.

El contexto de surgimiento del BNCCA tiene sus particularidades. Los estrechos vínculos trazados con la presidencia de Alvear de una generación de expertos formados entre las cátedras porteñas permitían un nuevo horizonte de posibilidades de reforma penal y penitenciaria, que había comenzado con la conformación del Centro de Estudios Penales en $1922^{67}$. Fue durante estos años en los cuales el reconocimiento de los estudios penitenciarios de Gómez se tradujo en la posibilidad de penetrar entre las instituciones y la toma de decisiones. El segundo gobierno de Irigoyen generó un distanciamiento de estas iniciativas a partir de 1928, pero las proyecciones previstas fueron un importante antecedente de la coyuntura inaugurada a partir de los años treinta; regida por la ley 11.833 sancionada en la década siguiente, y que marcará el comienzo de una nueva perspectiva en torno a las políticas públicas orientadas al castigo moderno. 
73 A diferencia de otros expertos penitenciarios del periodo, Gómez forjó su trayectoria institucional al calor de la docencia universitaria, siendo profesor de una de las primeras cátedras que se opuso a las políticas universitarias peronistas y que concluyó en una temprana renuncia: al respecto, en un texto reciente, González Alvo señalaba el carácter autodidacta en la formación de los principales cuadros penitenciarios a principios del siglo XX. Tanto Ballvé como Duffy habían formado parte de los escalafones de la policía, hasta asumir las direcciones del Asilo Correccional de Menores y la Penitenciaría Nacional respectivamente ${ }^{68}$.

En este sentido, se hace evidente la falta de capacidad del Estado argentino en generar cuadros administrativos para la inserción en las prisiones, cuestión que aún no ha sido indagada en profundidad. La relevancia de las revistas en la conformación de un dispositivo para la proyección de ideas y reformas será innegable, ya sea como escenario de discusiones expertas o como canalizadoras de emergentes lenguajes institucionales que articularán entre el saber y la práctica estatal. Este trabajo pretende inaugurar una serie de preguntas en torno a la conformación de saberes penitenciarios y sus diálogos con el estado argentino y las instituciones afines, cuestiones que encuentran - como intentamos demostrar - en las revistas un punto de referencia importante para acercarnos al complejo universo de las agencias estatales penitenciarias.

\section{Fuentes}

Biblioteca Nacional de Criminología y Ciencias Afines, Boletín de La Biblioteca Nacional de Criminología y Ciencias Afines, 3 tomos, Talleres Gráficos de la Penitenciaría Nacional, Buenos Aires, 1926-1929.

Penitenciaría Nacional de Buenos Aires, Catálogo que presentan sus diversos talleres a la exposición industrial conmemorativa del cincuentenario de la fundación del establecimiento, Talleres Gráficos de la Penitenciaría Nacional, Buenos Aires, 1927. 75 p.

77 Ministerio de Justicia e Instrucción Pública, Memoria presentada al H. Congreso de la Nación por el Ministro de Justicia e Instrucción Pública Dr. Antonio Sagarna. Año 1925, Tomo 1, Talleres Gráficos de la Penitenciaría Nacional, Buenos Aires, 1926.

78 Ministerio de Justicia e Instrucción Pública, Memoria presentada al H. Congreso de la Nación por el Ministro de Justicia e Instrucción Pública Dr. Antonio Sagarna. Año 1926, Tomo 1, Talleres Gráficos de la Penitenciaría Nacional, Buenos Aires, 1927.

79 Ministerio de Justicia e Instrucción Pública, Memoria presentada al H. Congreso de la Nación por el Ministro de Justicia e Instrucción Pública Dr. Antonio Sagarna. Año 1927, Tomo 1, Talleres Gráficos de la Penitenciaría Nacional, Buenos Aires, 1928. 


\section{BIBLIOGRAFÍA}

Abiuso, Federico, "Estudios carcelarios: un capítulo teórico-metodológico de la historia de Criminalogía Moderna", 1ras. Jornadas de Estudios sobre el Castigo, Universidad de Quilmes, Buenos Aires, 2018.

Albornoz, Martín, “Pietro Gori en la Argentina (1898-1902): anarquismo y cultura”, en Bruno, Paula (Ed.), Visitas culturales en la Argentina, 1898-1936, Biblos, Buenos Aires, 2014, p. 23-47.

Altamirano, Carlos, "Entre el naturalismo y la psicología: el comienzo de la 'ciencia social' en la Argentina”, en Neiburg, Federico G. \& Plotkin, Mariano Ben (Eds.), Intelectuales y expertos: la constitución del conocimiento social en la Argentina, Paidós, Buenos Aires, 2004, p. 31-65.

Baigún, David, “Ideas político-criminales del Código de 1921”, Nueva Doctrina Penal, 1997, p. 3-32.

Bohoslavsky, Ernesto \& Casullo, Fernando, "La cárcel de Neuquén y la política penitenciaria argentina en la primera mitad del siglo XX", Nueva Doctrina Penal, n 1, 2008, p. 295-314.

Caimari, Lila, Apenas un delincuente. Crimen, castigo y cultura en Buenos Aires, 1880-1940, Siglo XXI, Buenos Aires, 2004. 312 p.

Caimari, Lila \& Máximo Sozzo (Eds.), Historia de la cuestión criminal en América Latina, Prohistoria, Rosario, 2017. 386 p.

Creazzo, Giuditta, El positivismo criminológico italiano en la Argentina, Ediar, Buenos Aires, 2007. 259 p.

Dagrossa, Norberto C., "Índice general del Boletín de la Biblioteca Nacional de Criminología y Ciencias Afines", Revista de Historia del Derecho "R. Levene”, n³2, 1996, p. 277-302.

Dovio, Mariana, "El caso de la 'mala vida' en la Revista de Criminología, Psiquiatría y Medicina Legal (1914-1927) en Buenos Aires. Entre la peligrosidad y la prevención”, Revista de Historia del Derecho, n43, 2012, p. 1-29.

Dovio, Mariana, "La noción de la 'mala vida' en la revista Archivos de Psiquiatría, Criminología, Medicina Legal y Ciencias Afines, Buenos Aires (1902- 1913): en relación al higienismo argentino", Nuevo Mundo Mundos Nuevos, 2012. Disponible en: http://journals.openedition.org/ nuevomundo/63961 [Consultado el 29 de mayo de 2019]

Dovio, Mariana, "La peligrosidad en la revista de Criminología, Psiquiatría y Medicina Legal", Revista de Derecho Penal y Criminología, Vol. IV, n4 2014, p. 44-58.

Dovio, Mariana, "Medicina legal en Buenos Aires entre 1924-1934: proyectos legales sobre peligrosidad en la Revista de Criminología, Psiquiatría y Medicina Legal", Cuadernos de Historia, Santiago, $n^{\circ} 40,2014$, p. 95-114.

Elbert, Carlos Alberto, Manual básico de criminología, Eudeba, Buenos Aires, 2012. 318 p.

Flores, Valeria, "Los inicios del sistema carcelario en el Territorio Nacional de la Pampa (1884-1930)", Revista de Historia de las Prisiones, n¹, 2015, p. 53-77.

Galeano, Diego, “Civilización y delito. Notas sobre cuatro criminólogos argentinos”, Revista de Historia del Derecho, Buenos Aires, n45, 2013, p. 265-277. 
García Basalo, Juan Carlos, Historia de la Penitenciaría de Buenos Aires (1869-1880), Servicio Penitenciario Federal, Buenos Aires, 1979. 299 p.

García Basalo, Juan Pablo, "Medallística Penitenciaria. 8) Cincuentenario de la Penitenciaría Nacional (1927)”, Nueva Vida. Periódico cuatrimestral de la Asociación Mutual de Jefes y Oficiales Retirados del Cuerpo Penitenciario de la Nación, Vol. 2, n4, 1974, p. 12-17.

Gómez, Eusebio, Doctrina penal y penitenciaria, V. Abeledo, Buenos Aires, 1929. 264 p.

Gómez, Eusebio, El trabajo carcelario, Talleres Gráficos de la Penitenciaría Nacional, Buenos Aires, 1910. $15 \mathrm{p}$.

Gómez, Eusebio, Estudios penitenciarios, Talleres Gráficos de la Penitenciaría Nacional, Buenos Aires, 1906. 108 p.

Gómez, Eusebio, La Penitenciaría Nacional de Buenos Aires: Memoria descriptiva del establecimiento presentada por su director, Dr. Eusebio Gómez, al IX Congreso Penitenciario Internacional, reunido en Londres, Talleres Gráficos de la Penitenciaría Nacional, Buenos Aires, 1925. 190 p.

González Alvo, Luis, “Una aproximación a los orígenes de la administración penitenciaria federal. Las 'comisiones de cárceles' y el proyecto de reformas de Claros y Muratgia (1890-1912)”, Anuario del Instituto de Historia Argentina, Vol. 17, n¹, 2017, p. 1-25.

González Alvo, Luis, “La recepción de las nuevas ideas penales y criminológicas en Tucumán (1880-1916)”, Revista de Historia del Derecho, n43, 2012, p. 64-101.

González Alvo, Luis, Modernizar el castigo: la construcción del régimen penitenciario en Tucumán, 1880-1916, Rosario, Prohistoria, 2013. 218 p.

González, Esteban, "Circulación de saberes penales en la Facultad de Derecho y Ciencias Sociales. El caso de la Revista Penal Argentina", en Carrasco, Morita \& Luxardo, Natalia (Eds.), El orden cuestionado. Lecturas de antropología jurídica, Universidad Nacional de General Sarmiento, Buenos Aires, 2017, p. 25-41.

González, Esteban, "El trabajo de los penados argentinos alrededor del mundo. Eusebio Gómez en el IX Congreso Penitenciario Internacional (Londres, 1925)”, Revista de Historia de las Prisiones, $\mathrm{n}^{\circ} 7$, 2018, p. 28-48.

Instituto de Criminología de la Peniteniciaría Nacional, Trabajos y actas del Congreso Penitenciario Nacional celebrado en Buenos Aires del 4 al 11 de Mayo de 1914, Talleres Gráficos de la Penitenciaría Nacional, Buenos Aires, 1914. 303 p.

Laplaza, Francisco P., “Antecedentes de nuestro periodismo forense hasta la aparición de la Revista Criminal (1873), como introducción a la historia del derecho penal argentino", Revista Penal y Penitenciaria, Vol. X, n³5/38, 1945, p. 49-298.

Luciano, Milena, “La Penitenciaría de Córdoba: proceso de construcción, régimen interno y tensiones institucionales, 1887-1907”, Prohistoria, Vol. 21, 2014, p. 131-155.

Luciano, Milena, "La verdad burocratizada: las condiciones materiales de vida de los internos de la Penitenciaría de Córdoba entre 1908 y 1916”, Revista de Historia de las Prisiones, n6, 2018, p. 144-157.

Luciano, Milena, "Las ideas penitenciarias en el campo jurídico cordobés. 1885-1911", Anuario de la Escuela de Historia Virtual, Vol. 4, n4, 2013, p. 75-92.

Marteau, Juan Félix, Las palabras del orden: proyecto republicano y cuestión criminal en Argentina (Buenos Aires, 1880-1930), Editores Del Puerto, Buenos Aires, 2003. 193 p. 
Moreno, Rodolfo, El problema penal, Talleres Gráficos Argentinos L. J. Rosso, Buenos Aires, 1933. $170 \mathrm{p}$.

Navas, Pablo, La construcción de soberanía y el control social en la periferia patagónica desde la cárcel de Río Gallegos (1895-1957), Tesis de doctorado en historia, Universidad Nacional de La Plata, La Plata, 2013. 263 p. Disponible en: http://www.memoria.fahce.unlp.edu.ar/tesis/te.798/te.798.pdf [Consultado el 29 de mayo de 2019]

Núñez, Jorge, "La reforma penitenciaria peronista vista desde España: análisis de la gestión de Roberto Pettinato en la Revista de la Escuela de Estudios Penitenciarios (Madrid, 1947-1958)", Anuario de Derecho Penal y Ciencias Penales, Vol. 69, n¹, 2016, p. 449-480.

Núñez, Jorge \& González Alvo, Luis, "La gran fuga de la Penitenciaría Nacional”, Todo es Historia, Vol. 5, n586, 2016, p. 22-30.

Olaeta, Hernan, “Apuntes sobre la historia de las estadísticas penitenciarias en Argentina, 1906-2016”, Revista de Historia de las Prisiones, n6, 2018, p. 70-96.

Olmo, Rosa del, América Latina y su criminología, Siglo XXI, México, 1981. 272 p.

Olmo, Rosa del, Criminología argentina. Apuntes para su reconstrucción histórica, Ediciones De Palma, Buenos Aires, 1992. 71 p.

Piazzi, Carolina, Justicia criminal y cárceles en Rosario: segunda mitad del siglo XIX, Prohistoria Ediciones, Rosario, 2011. 125 p.

Pugliese, María Rosa, "Las revistas jurídicas en la Argentina en la primera mitad del siglo XX: una mirada cultural y didáctica sobre el género", Revista de Historia del Derecho, n47, 2014, p. 105-148.

Rodriguez, Julia, Civilizing Argentina: Medicine, Science and the Modern State, University of North Carolina Press, Chapel Hill, 2006. 306 p.

Rotondo, Francesco, Itinerari alla Periferia di Lombroso: Pietro Gori e la Criminalogia Moderna in Argentina, Editoriale Scientifica, Napoli, 2014. 207 p.

Ruibal, Beatriz, Ideología del control social. Buenos Aires, 1880-1920, Centro Editor de América Latina, Buenos Aires, 1993. 80 p.

Salessi, Jorge, Médicos, maleantes y maricas. Higiene, criminología y homosexualidad en la construcción de la nación argentina (Buenos Aires, 1871-1914), Beatriz Viterbo Editora, Rosario, 2000. 413 p.

Salvatore, Ricardo, “Usos científicos en 'La mala vida' de Eusebio Gómez”, en Salvatore, Ricardo \& Barreneche, Osvaldo (Eds.), El delito y el orden en perspectiva histórica, Prohistoria Ediciones, Rosario, 2013, p. 99-120.

Salvatore, Ricardo \& Aguirre, Carlos (Eds.), The Birth of the Penitentiary in Latin America: Essays on Criminology, Prison Reform, and Social Control, 1830-1940, University of Texas Press, Austin, 1996. 279 p.

Silva, Jeremías, “Difundir el 'Penitenciarismo Justicialista': la Revista Penal y Penitenciaria, 1946-1953”, en Panella, Claudio \& Korn, Guillermo (Eds.), Ideas y debates para la nueva Argentina: revistas culturales y politicas del Peronismo (1946-1955), Universidad Nacional de La Plata, Ediciones de Periodismo y Comunicación, La Plata, 2010, p. 139-168.

Silva Riestra, Juan, Evolución de la enseñanza del Derecho Penal en la Universidad de Buenos Aires, Imprenta de la Universidad, Buenos Aires, 1943.59 p.

Sozzo, Máximo, Historias de la cuestión criminal en la Argentina, Editores del Puerto, Buenos Aires, 2009. $398 \mathrm{p}$. 
Sozzo, Máximo, "Los usos de Lombroso: tres variantes en el nacimiento de la criminología positivista en Argentina", en Caimari, L. \& Sozzo, M. (Eds.), Historia de la cuestión criminal en América Latina, Prohistoria, Rosario, 2017, p. 27-70.

Sozzo, Máximo, “Retratando al 'homo criminalis': esencialismo y diferencia en las representaciones 'profanas' del delincuente en la Revista Criminal (Buenos Aires, 1873)", en Caimari, Lila (Comp.), La ley de los profanos: delito, justicia y cultura en Buenos Aires (1870-1940), Fondo de Cultura Económica, Buenos Aires, 2007, p. 23-66.

Tau Anzoátegui, Víctor (Ed.), La Revista Jurídica en la cultura contemporanea, Ediciones Ciudad Argentina, Buenos Aires, 1997. 389 p.

Zaffaroni, Eugenio, "La mala vida o los prejuicios vestidos de ciencia”, en Miranda, Marisa \& Vallejo, Gustavo (Eds.), Una historia de la eugenesia. Argentina y las redes biopolíticas internacionales, 1912-1945, Biblos, Buenos Aires, 2012, p. 123-140.

Zaffaroni, Eugenio, “Prólogo", en Gómez, Eusebio, La Mala Vida en Buenos Aires, Biblioteca Nacional, Buenos Aires, 2012, p. 9-28.

\section{NOTAS}

1. Cfr. Altmirano, Carlos, "Entre el naturalismo y la psicología: el comienzo de la 'ciencia social' en la Argentina", en Neiburg, Federico \& Plotkin, Mariano (Eds.), Intelectuales y expertos: la constitución del conocimiento social en la Argentina, Paidós, Buenos Aires, 2004, p. 36-37. Este texto forma parte de las actividades del Proyecto PICT 2015-2314 "Policía, redes transnacionales y prácticas delictivas en la Argentina, siglos XIX y XX”, dirigido por el Dr. Eduardo Zimmermann y financiado por la Agencia Nacional de Investigación Científica y Tecnológica de Argentina

2. Ver: Sozzo, Máximo, Historias de la cuestión criminal en la Argentina, Editores del Puerto, Buenos Aires, 2009. Una actualización muy importante al respecto es Caimari, Lila \& Sozzo, Máximo (Eds.), Historia de la cuestión criminal en América Latina, Prohistoria, Rosario, 2017.

3. Sozzo, Máximo, “Retratando al 'homo criminalis': esencialismo y diferencia en las representaciones 'profanas' del delincuente en la Revista Criminal (Buenos Aires, 1873)”, en Caimari, Lila (Comp.), La ley de los profanos: delito, justicia y cultura en Buenos Aires (1870-1940), Fondo de Cultura Económica, Buenos Aires, 2007. Para las publicaciones previas a la Revista Criminal, ver: Laplaza, Francisco P., "Antecedentes de nuestro periodismo forense hasta la aparición de la Revista Criminal (1873), como introducción a la historia del derecho penal argentino", Revista Penal y Penitenciaria, Vol. X, n³5/38, 1945, p. 49-298.

4. Eusebio Gómez nació en la provincia de Santa Fe, Argentina. Fue hijo de un destacado profesor y diputado de aquella provincia, se formó como abogado y obtuvo el grado de doctor en 1902. A partir de aquel entonces participó activamente en el ejercicio de la abogacía, aunque revelando una clara veta por la investigación en cuestiones penales y penitenciarias. En los años veinte fue nombrado profesor titular de la cátedra de Derecho Penal de la carrera de Derecho en la Universidad de Buenos Aires, cargo que sostuvo hasta mediados de la década del cuarenta, tras la intervención de la universidad porteña. Gómez dirigió la Penitenciaría Nacional desde 1923 hasta 1928, cuando fue designado juez de Instrucción Pública en Segunda Instancia por la Capital Federal. En los años treinta trabajó junto a Rodolfo Moreno (en el Proyecto de Código de Procedimientos en Materia Penal) y Jorge Eduardo Coll (en el Proyecto de Código Penal). A lo largo de su trayectoria escribió docenas de artículos, dirigió varias revistas (además del BBNCCA, estuvo al frente de la Revista de Derecho Penal durante sus dos etapas, 1929-1930 y 1945-1951) y publicó más de veinte libros, destacables entre ellos -además de los citados a lo largo de este 
artículo- el Tratado de Derecho Penal (seis tomos, publicados entre 1939 y 1942) y Leyes Penales Anotadas (cuatro tomos, publicados entre 1952 y 1954). Falleció en 1954, en Buenos Aires.

5. El corpus generado al respecto es bastante importante. Acerca de la relevancia de las revistas en la conformación de un lenguaje criminológico local, la obra fundante de Rosa del Olmo continúa siendo hoy en día una referencia obligada. Ver: Del Olmo, Rosa, América Latina y su criminología, Siglo XXI, México, 1981, p. 223-248.; Criminología Argentina: apuntes para su reconstrucción histórica, Ediciones De Palma, Buenos Aires, 1992. Por mencionar algunas referencias con respecto a las revistas jurídicas, ver: Tau Anzoátegui, Víctor (Ed.), La revista jurídica en la cultura contemporanea, Ediciones Ciudad Argentina, Buenos Aires, 1997; y, en especial los siguientes trabajos: María Rosa Pugliese, "Las revistas jurídicas en la Argentina en la primera mitad del siglo XX: Una mirada cultural y didáctica sobre el género", Revista de Historia del Derecho , nº47, 2014, p. 105-148; Dovio, Mariana, "La peligrosidad en la Revista de Criminología, Psiquiatría y Medicina Legal“, Revista de Derecho Penal y Criminología, Vol. IV, nº4, 2014, p. 44-58; "La noción de la 'mala vida' en la Revista Archivos de Psiquiatría, Criminología, Medicina Legal y Ciencias Afines, Buenos Aires (1902- 1913) en relación al higienismo argentino", Nuevo mundo mundos nuevos, 2012. Disponible en: http://journals.openedition.org/nuevomundo/63961 [Consultado el 29 de mayo de 2019]; "Medicina legal en Buenos Aires entre 1924-1934: Proyectos legales sobre peligrosidad en la Revista de Criminología, Psiquiatría y Medicina Legal", Cuadernos de Historia, Santiago, nº40, 2014, p. 95-114; "El caso de la 'mala vida'; en la Revista de Criminología, Psiquiatría y Medicina Legal (1914-1927) en Buenos Aires: entre la peligrosidad y la prevención", Revista de Historia del Derecho, $\mathrm{n}^{\circ}$ 43, 2012, p. 1-29. Para la Revista Penal y Penitenciaria, el trabajo de Jeremías Silva propone una perspectiva muy interesante acerca de los alcances de la política social justicialista a través de la publicación argentina en: Silva, Jeremías, "Difundir el 'Penitenciarismo Justicialista': la Revista Penal y Penitenciaria, 1946-1953”, en Panella, Claudio \& Korn, Guillermo (Eds.), Ideas y debates para la nueva Argentina: revistas culturales y politicas del peronismo (1946-1955), Universidad Nacional de La Plata/Ediciones de Periodismo y Comunicación, La Plata, 2010, p. 139-168. Una perspectiva internacional acerca del mismo fenómeno en: Núñez, Jorge, "La reforma penitenciaria peronista vista desde España: análisis de la gestión de Roberto Pettinato en la Revista de la Escuela de Estudios Penitenciarios (Madrid, 1947-1958)", Anuario de Derecho Penal y Ciencias Penales, Vol. 69, n¹, 2016, p. 449-480.

6. La importancia de las construcciones penitenciarias para los estados latinoamericanos fue recalcada por Carlos Aguirre y Ricardo Salvatore en uno de los trabajos fundacionales acerca de las prisiones en Latinoamérica. Para el último cuarto del siglo XIX eran muy pocos los estados que pudieron construir sus penitenciarias, a excepción de Brasil, Perú y Argentina. Ver: Salvatore, Ricardo \& Aguirre, Carlos (Eds.), The Birth of the Penitentiary in Latin America: Essays on Criminology, Prison Reform, and Social Control, 1830-1940, University of Texas Press, Austin, 1996, p. 9 y ss.; Caimari, Lila, Apenas un delincuente. Crimen, castigo y cultura en Buenos Aires, 1880-1940, Siglo XXI, Buenos Aires, 2004, p. 50 y ss.

7. El desarrollo de la criminología en Argentina, en relación con otros países de la región, fue bastante temprano. La cantidad de investigaciones acerca de la cuestión conforma actualmente un corpus inmenso de bibliografía imposible de resumir en una nota. Sin ser exhaustivos, entre las principales referencias podemos mencionar los textos pioneros de Rosa del Olmo (ver nota 4). Ver también: Ruibal, Beatriz, Ideología del control social: Buenos Aires 1880-1920, Centro Editor de América Latina, Buenos Aires, 1993; Salessi, Jorge, Médicos, maleantes y maricas: Higiene, criminología y homosexualidad en la construcción de la nación argentina (Buenos Aires, 1871-1914), Beatriz Viterbo Editora, Rosario, 2000; Marteau, Juan Félix, Las palabras del orden: Proyecto republicano y cuestión criminal en Argentina (Buenos Aires, 1880-1930), Editores Del Puerto, Buenos Aires, 2003; Creazzo, Giuditta, El positivismo criminológico italiano en la Argentina, Ediar, Buenos Aires, 2007. 
8. El estudio de las prisiones fuera de Buenos Aires ha crecido exponencialmente en los últimos años, supliendo parcialmente la ausencia de estudios de caso. En este sentido, se ha prestado atención a algunas experiencias provinciales hacia el interior del país, como Tucumán: González Alvo, Luis, "La recepción de las nuevas ideas penales y criminológicas en Tucumán (1880-1916)", Revista de Historia del Derecho, nº3, 2012, p. 64-101; González Alvo, Luis Gabriel, Modernizar el castigo: La construcción del régimen penitenciario en Tucumán, 1880-1916, Prohistoria, Rosario, 2013. Sobre el caso de Córdoba: Luciano, Milena, "La verdad burocratizada: las condiciones materiales de vida de los internos de la Penitenciaría de Córdoba entre 1908 y 1916", Revista de Historia de las Prisiones, n6, 2018, p. 144-157; Luciano, Milena, "La Penitenciaría de Córdoba: proceso de construcción, régimen interno y tensiones institucionales, 1887-1907", Prohistoria, Vol. 21, 2014, p. 131-155; Luciano, Milena, "Las ideas penitenciarias en el campo jurídico cordobés, 1885-1911", Anuario de la Escuela de Historia Virtual, Vol. 4, nº4, 2013, p. 75-92. En Neuquén: Bohoslavsky, Ernesto \& Casullo, Fernando, "La cárcel de Neuquén y la política penitenciaria argentina en la primera mitad del siglo XX”, Nueva Doctrina Penal, nº1, 2008, p. 295-314. En Santa Fe: Piazzi, Carolina, Justicia criminal y cárceles en Rosario: segunda mitad del siglo XIX, Prohistoria Ediciones, Rosario, 2011. En La Pampa: Flores, Valeria, "Los inicios del sistema carcelario en el Territorio Nacional de la Pampa (1884-1930)”, Revista de Historia de las Prisiones, $\mathrm{n}^{\circ} 1$, 2015, p. 53-77. En el caso de Santa Cruz: Navas, Pablo, La construcción de soberanía y el control social en la periferia patagónica desde la cárcel de Río Gallegos (1895-1957), Tesis de doctorado en historia, Universidad Nacional de La Plata, La Plata, 2013. Disponible en: http://www.memoria.fahce.unlp.edu.ar/tesis/te.798/ te.798.pdf [Consultado el 29 de mayo de 2019] La más importante y duradera de todas ellas, la Penitenciaría de Buenos Aires -nacionalizada en 1880-, todavía no ha sido objeto de un estudio específico de largo alcance.

9. Olmo, Rosa del, América Latina y su criminología, Op. Cit., p. 150.

10. Confirman esta perspectiva Olmo, R. del, Criminología Argentina, Op. Cit.; Rodriguez, Julia, Civilizing Argentina: Medicine, Science and the Modern State, University of North Carolina Press, Chapel Hill, 2006.

11. Máximo Sozzo interpreta el complejo proceso de recepción de las ideas de Lombroso en Argentina a partir de tres instancias sucesivas basadas en la adopción, la transacción y el rechazo. Ver: Sozzo, Máximo, "Los usos de Lombroso: tres variantes en el nacimiento de la criminología positivista en Argentina", en Caimari, Lila M. \& Sozzo, Máximo (Eds.), Historia de la cuestión criminal en América Latina, Prohistoria, Rosario, 2017, p. 386.

12. Rodriguez, J., Civilizing Argentina, Op. Cit.; Albornoz, Martín, "Pietro Gori en la Argentina (1898-1902): anarquismo y cultura”, en Bruno, Paula (Ed.), Visitas culturales en la Argentina, 1898-1936, Biblos, Buenos Aires, 2014, p. 23-47; Rotondo, Francesco, Itinerari alla periferia di Lombroso: Pietro Gori e la Criminalogia Moderna en Argentina, Editoriale Scientifica, Napoli, 2014.

13. Al respecto: Abiuso, Federico, "Estudios carcelarios: un capítulo teórico-metodológico de la historia de Criminalogía Moderna", 1ras. Jornadas de Estudios sobre el Castigo, Universidad de Quilmes, Buenos Aires, 2018.

14. El plantel era completado por escritores internacionales de la talla de Cesare Lombroso, Enrico Ferri, Pedro Figari, Charles Aldermann, Scipio Sighele, Agustín Hamon, Napoleon Colajanni, Raffaele Garofalo y Guglielmo Ferrero. Localmente, acompañaban a Gori en la escritura de la revista Guillermo Achával, Francisco de Veyga, Antonio Dellepiane, Luis M. Drago, Victor Arreguine, Manuel Carlés, y Juan Vucetich.

15. Duffy, Luis, "La Nueva Revista. Su programa", Revista Penitenciaria, Vol. 1, nº 1, 1905. La revista, de publicación bimestral, es muy difícil de hallar en bibliotecas y repositorios argentinos en la actualidad.

16. Solo en el primer número se utilizará la denominación "criminalogía”, acuñada por Pietro Gori con el sentido de centralizar el enfoque en el criminal. Para los meses y años siguientes, Ingenieros se decidirá por la denominación más difundida del término. A partir del segundo año, 
el nombre de la publicación se ampliará hacia otros horizontes teóricos bajo el título Archivos de Psiquiatría y Criminología aplicadas a las ciencias afines. Medicina Legal, Sociología, Derecho, Psicología. Pedagogía. Para 1907, el título se acortará considerablemente a Archivos de Psiquiatría y Criminología aplicadas a las ciencias afines.

17. Una mayor permeabilidad de la cuestión penitenciaria se evidencia a partir del funcionamiento del Instituto de Criminología en la Penitenciaría Nacional dirigida por Antonio Ballvé. Si bien no se convirtió en el órgano oficial de la institución, es notable la paulatina cantidad de documentación publicada.

18. Por ejemplo: Creazzo, G., El positivismo criminológicos, Op. Cit.; Elbert, Carlos Alberto, Manual básico de criminología, Eudeba, Buenos Aires, 2012; Olmo, R. del, Criminología Argentina, Op. Cit.

19. Una de las pocas reseñas que encontramos acerca de la tesis de Gómez fue la publicada durante el primer año de los Archivos, que sostenía lo siguiente: "es el trabajo de un joven que ha procurado reemplazar la experimentación personal con la inteligencia y la erudición. Está escrito con método y claridad, se deja leer con provecho, como trabajo de resumen. Llega a las siguientes conclusiones: $1^{\circ}$ las autosugestiones y las sugestiones provocadas durante el sueño hipnótico demuestran que la conciencia de la libertad moral es pura ilusión; $2^{\circ}$ La comisión de un delito sugerido durante el hipnotismo puede ser castigado porque el agente es irresponsable; $3^{\text {o }}$ la dificultad de probar la sugestión hipnótica no justifica el silencio de la ley respecto de este fenómeno", S. H. [Pseud.], "Sugestión y responsabilidad criminal, Eusebio Gómez. Buenos Aires, 1902 (tesis) [reseña]”, Archivos de Criminalogía, Medicina Legal y Psiquiatría, Vol. 1, 1902, p. 504.

20. Gómez, Eusebio, Estudios Penitenciarios, Talleres Gráficos de la Penitenciaría Nacional, Buenos Aires, 1906, p. 57.

21. La lectura propuesta por Zaffaroni hace hincapié en las limitaciones teóricas del texto de Gómez, cuyas interpretaciones serán cuestionadas por Ricardo Salvatore. Zaffaroni, Eugenio, "La mala vida o los prejuicios vestidos de ciencia”, en Miranda, Marisa \& Vallejo, Gustavo (Eds.) , Una historia de la eugenesia. Argentina y las redes biopolíticas internacionales, 1912-1945, Biblos, Buenos Aires, 2012; Zaffaroni, Eugenio, "Prólogo", La mala vida en Buenos Aires, Biblioteca Nacional, Buenos Aires, 2012; Salvatore, Ricardo, “Usos científicos en 'La mala vida' de Eusebio Gómez”, en Salvatore, Ricardo \& Barreneche, Osvaldo (Eds.), El delito y el orden en perspectiva histórica, Prohistoria Ediciones, Rosario, 2013, p. 99-120. Al respecto, ver también: Galeano, Diego, “Civilización y delito. Notas sobre cuatro criminólogos argentinos", Revista de Historia del Derecho, Buenos Aires, n45, 2013, p. 265-277.

22. Salvatore, R., “Usos científicos”, Op. Cit., p. 101.

23. Gómez, Eusebio, "La mala vida en Buenos Aires", Archivos de Psiquiatría y Criminología aplicadas a las ciencias afines, Vol. VI, 1907, p. 431-442.

24. Gómez, Eusebio, El trabajo carcelario, Talleres Gráficos de la Penitenciaría Nacional, Buenos Aires, 1910, p. 2.

25. Una extensa reseña de Criminología Argentina, firmada por Helvio Fernández, apareció en los Archivos.

26. Gómez, Eusebio, "El problema penal argentino", Archivos de Psiquiatría y Criminología aplicadas a las ciencias afines, Vol. XI, 1912, p. 394.

27. Gómez, Eusebio, Doctrina Penal y Penitenciaria, V. Abeledo, Buenos Aires, 1929, p. 16.

28. La Comisión directiva del congreso estaba presidida por Norberto Piñero (por aquellos años, titular de la cátedra de Derecho Penal en la Facultad de Derecho y Ciencias Sociales de la Universidad de Buenos Aires). Acompañaban Osvaldo Piñero, Domingo Cabred, Ricardo Seeber, y Domingo Cavia (como vicepresidentes). Helvio Fernández y Eusebio Gómez, junto con Miguel Lancelotti y Carlos de Arenaza serán nombrados como secretarios y prosecretarios respectivamente. Instituto de Criminología de la Peniteniciaría Nacional, Trabajos y actas del Congreso Penitenciario Nacional celebrado en Buenos Aires del 4 al 11 de Mayo de 1914, Talleres Gráficos de la Penitenciaría Nacional, Buenos Aires, 1914, p. 12. 
29. Gran parte de las resoluciones del Congreso fueron publicadas también en los Archivos. Ver especialmente: Vol. XI, 1910.

30. Cfr. Silva Riestra, Juan, Evolución de la enseñanza del Derecho Penal en la Universidad de Buenos Aires, Imprenta de la Universidad, Buenos Aires, 1943.

31. Baigún, David, "Ideas político-criminales del código de 1921", Nueva Doctrina Penal, 1997, p. 3-32.

32. Cfr. González, Esteban, "Circulación de saberes penales en la Facultad de Derecho y Ciencias Sociales. El caso de la Revista Penal Argentina”, en Carrasco, Morita \& Luxardo, Natalia (Eds.), El orden cuestionado. Lecturas de antropología jurídica, Universidad Nacional de General Sarmiento, Buenos Aires, 2017, p. 25-41.

33. El Censo fue, con respecto al primero organizado para 1906, un completo fracaso. Acerca de la historia de la estadística criminal, ver: Olaeta, Hernan, "Apuntes sobre la historia de las estadísticas penitenciarias en Argentina, 1906-2016”, Revista de Historia de las Prisiones, n6, 2018, p. 70-96.

34. Citado por Gómez de la revista L' Ecrou, argumentando que: “(...) el Boletín editado por la misma ha logrado un éxito que, en verdad, no sospeché. Todas las revistas de la especialidad, de Europa y América, han señalado su originalidad y, sobre todo, los grandes servicios que, como fuente de información, puede prestar a los que se consagran a la criminología y demás disciplinas afines". Gómez, Eusebio, "Penitenciaría Nacional. Informe de la Dirección [año 1926]”, Boletín de la Biblioteca Nacional de Criminología y Ciencias Afines, Vol. II, nº6, 1927, p. 162.

35. Apareció también impreso este decreto en la contraportada del primer número, luego reemplazado por el correspondiente índice. Se menciona también que los gastos de la Biblioteca formarán parte de las partidas asignadas por la Ley de Presupuesto y que sus servicios se atenderán con el personal del mismo, en la forma que disponga la Dirección (Art $3^{\circ}$ ). Ministerio de Justicia e Instrucción Pública, Memoria presentada al H. Congreso de la Nación por el Ministro de Justicia e Instrucción Pública Dr. Antonio Sagarna. Año 1925, Talleres Gráficos de la Penitenciaría Nacional, Buenos Aires, 1926, p. 158-159.

36. Dagrossa, Norberto C., "Índice general del Boletín de la Biblioteca Nacional de Criminología y Ciencias Afines", Revista de Historia del Derecho "R. Levene", n³2, 1996, p. 277-302. El índice, de inmensa utilidad para la redacción de este trabajo, presenta varios errores en la presentación de los datos.

37. En el informe correspondiente al año 1925 se anuncia en la sección del Instituto de Criminología: “(...) este Instituto se permite recabar, de quien corresponda, el pronto despacho de los muebles que en oportunidad se solicitaron de la sección Talleres (...) a los efectos de ubicar en ellos, el voluminoso archivo que posee. Esta necesidad es tanto más sentida, cuando esa Dirección ha resuelto, a los fines de dar cumplimiento a lo dispuesto por el Decreto del P. E. De fecha 19 de noviembre de 1925, ubicar en uno de los salones de este Instituto, la Biblioteca Nacional de Criminología y Ciencias Afines que se ha proyectado, y cuya formación está en vías de realizarse". Cfr. Ministerio de Justicia e Instrucción Pública, Memoria presentada al H. Congreso, Op. Cit., p. 421.

38. Dagrossa, N., “Índice general”, Op. Cit., p. 278.

39. Gómez, E., “Penitenciaría Nacional. Informe de la Dirección [año 1926]”, Op.Cit., p. 155.

40. Sucederá a Gómez en el máximo cargo de la institución, el subdirector José Cabrini, quien será un cuadro clave en la gestión del edificio por más de veinte años de su vida. Mientras tanto, Gómez será rápidamente incorporado al juzgado de Capital Federal.

41. La situación financiera de los proyectos editoriales muy pocas veces llama la atención de sus lectores. Los bajísimos costos de producción del boletín fueron fácilmente costeados por los Talleres Gráficos de la Penitenciaría Nacional, que en 1925 había adquirido nuevas maquinarias Intertype para la impresión y composición de materiales gráficos, principalmente el Boletín oficial 
y el Boletín Judicial, de impresión diaria. Ver Gómez, E., "Penitenciaría Nacional. Informe de la Dirección [año 1926]", Op. Cit., p. 153.

42. La única excepción es una reseña del libro La intervención del Estado en la peligrosidad predilectual de Sebastián Soler, que fue firmada por F. A. C. Varias de las demás reseñas aparecen en otras publicaciones en las cuales Gómez colaboró (como la Revista Penal Argentina), o dirigió (como la Revista de Derecho Penal).

43. En la primera aparición, una nota al pie sostenía: “en esta sección del Boletín se publicarán notas bibliográficas acerca de las obras que, sobre criminología y ciencias afines, nos seas remitidas en dos ejemplares, y sobre los artículos de doctrina que se publiquen en las revistas de canje". Boletín de la Biblioteca Nacional de Criminología y Ciencias Afines, Talleres Gráficos de la Penitenciaría Nacional, Buenos Aires, 1926, p. 83.

44. La recopilación aludida se tituló Doctrina Penal y Penitenciaria (1929), obra en donde el autor sintetizó la importante obra práctica y teórica emprendida durante las primeras décadas. El libro será próximamente reeditado como parte de la colección Criminología Argentina, dirigida por José Daniel Cesano y Jorge Núñez.

45. En el artículo de Jeremías Silva, también presente en este dossier, se aborda la publicación de esta revista.

46. Fue publicado un texto de Fernando Cadalso, acerca de La Bastilla francesa.

47. Aquel año se produjo la segunda gran fuga colectiva de la Penitenciaría Nacional, de amplísima cobertura por los medios de prensa locales. El episodio, bautizado como "la fuga de los catorce", hacía alusión a la cantidad de hombres que escaparon a través de un boquete de cincuenta y cinco metros de longitud, que unía el taller de escobería con la avenida Juncal por debajo de las murallas de concreto del penal. Las investigaciones demostraron que la excavación no había sido un plan azaroso, sino producto de una compleja coordinación que sucedió a las espaldas de Ramos, el interventor de la Penitenciaría Nacional. La repercusión del evento adelantó el fin de la intervención y la posterior designación de Gómez como nuevo director. Ver: Núñez, Jorge \& González Alvo, Luis, "La gran fuga de la Penitenciaría Nacional”, Todo es Historia, n '586, 2016, p. 22-30.

48. Moreno, Rodolfo, El problema penal, Talleres Gráficos Argentinos L. J. Rosso, Buenos Aires, 1933, p. 136.

49. En el informe correspondiente al año 1926, Gómez responde a los comentarios provenientes de la prensa acerca de que "las 'comodidades' y 'atractivos' de la prisión representan estímulos para la actividad inicua de los delincuentes. El director recurre al argumento constitucional que rige el pensamiento de los penitenciaristas argentinos: [la Penitenciaría Nacional] es un establecimiento limpio (...) que se ha instituido para seguridad y no para castigo de los detenidos en él”. Gómez, E., "Penitenciaría Nacional. Informe de la Dirección [año 1926]”, Op. Cit., p. 156-157.

50. Gómez, E., Doctrina Penal y Penitenciaria, Op. Cit., p. 174. La disciplina era administrada por un Tribunal de Conducta, el cual estaba integrado por los empleados superiores: el subdirector como presidente, y el director de la Escuela y el jefe de la sección penal como vocales. La clasificación, que se hacía luego de los sesenta días del ingreso a la Penitenciaría, iba desde "conducta pésima" a "conducta ejemplar": esta escala reglaba restricciones o beneficios graduales, como número de visitas mensuales, acceso a la luz de noche, número de correspondencia enviada y recibida, etcétera. Para formular la clasificación, el Tribunal tenía en cuenta el comportamiento en el pabellón, taller y escuela; la asistencia al taller y escuela; los progresos, ya sea como obrero y/o como alumno; las tendencias en su carácter; su moralidad, etcétera.

51. La exposición de motivos del Reglamento en: Ministerio de Justicia e Instrucción Pública, Memoria presentada al H. Congreso, Op. Cit., p. 95-102. Llama la atención la omisión en esta exposición de motivos de otros intentos anteriores de reglamentación de la Penitenciaría Nacional, como por ejemplo el presentado en 1910 por el subdirector Rafael Súnico y transcripto 
en Archivos, precedido por el texto "Sobre régimen penitenciario" del mismo Gómez. Cfr. Gómez, Eusebio, "Sobre régimen penitenciario", Archivos de Psiquiatría y Criminología aplicadas a las ciencias afines, Vol. IX, 1910, p. 201-203; Súnico, Rafael, "Penitenciaría Nacional. Proyecto de Reglamento general presentado al Ministerio de Justicia e Instrucción Pública”, Archivos de Psiquiatría y Criminología aplicadas a las ciencias afines, Vol. IX, 1910, p. 204-253.

52. "Art. 129. A todo penado que sufra un accidente en el trabajo, ya sea en los talleres o fuera de éstos, por el cual se vea obligado a permanecer en asistencia médica, se le liquidará el peculio durante el tiempo de su incapacidad para el trabajo, en la misma proporción que le correspondería si se encontrase trabajando". Ministerio de Justicia e Instrucción Pública, Memoria presentada al H. Congreso, Op. Cit. Sin embargo, la orden del día n¹80, del 24 de enero de 1906, resolvía el pago total del peculio trabajado a todo penado o detenido que sufriera algún accidente en el trabajo, ya sea en los talleres o fuera de ellos, mientras guarde reposo en la enfermería mientras se encuentre trabajando.

53. La participación argentina en este evento fue singular en al menos cuatro tópicos: a) por la iniciativa del Ministerio de Justicia de conformar una comisión integrada por expertos en materia penal y penitenciaria, a diferencia de las participaciones anteriores; b) por la defensa de ideas de organización de los penados alternativas a las propuestas de los positivistas italianos; c) por la preocupación local en la generación de documentación para enviar al Congreso Penitenciario Internacional; y d) por la integración con participaciones estudiantiles, manifiesta en la presentación de textos generados por los estudiantes de los seminarios dictados en la Facultad de Derecho de la Universidad de Buenos Aires Ver: González, Esteban, "El trabajo de los penados argentinos alrededor del mundo. Eusebio Gómez en el IX Congreso Penitenciario Internacional (Londres, 1925)", Revista de Historia de las Prisiones, $n^{\circ} 7,2018$, p. 28-48.

54. Gómez, Eusebio, La Penitenciaría Nacional de Buenos Aires: Memoria descriptiva del establecimiento, presentada por su director, Dr. Eusebio Gómez, al IX Congreso Penitenciario Internacional reunido en Londres, Talleres Gráficos de la Penitenciaría Nacional, Buenos Aires, 1925, p. 129-130. Aunque la existencia de una Escuela de Penados data de principios del siglo, la Escuela de Celadores y Guardiacárceles figura en informes y notas publicadas por Gómez, pero aún no pudimos dar con datos concisos acerca de su efectiva puesta en funcionamiento.

55. Estas eran "Historia argentina”, "Higiene”, “Geografía”, “Instrucción cívica”, "Enseñanza moral y profesional” y "Régimen carcelario teórico-práctico".

56. Gómez, E., Doctrina Penal y Penitenciaria, Op. Cit., p. 180.

57. Gómez, Eusebio, “Penitenciaría Nacional. Informe de su redacción [1927]”, Boletín de la Biblioteca Nacional de Criminología y Ciencias Afines, Vol. II, nº 8, 1928, p. 443.

58. Gómez, Eusebio, “Cincuentenario de la Penitenciaría Nacional. Exposición de su industria”, Boletín de la Biblioteca Nacional de Criminología y Ciencias Afines, Vol. II, n², 1927, p. 67.

59. Ibíd., p. 68-69.

60. La Penitenciaría nunca tuvo un acto inaugural, ya que su puesta en funcionamiento se dio bajo un sorprendente silencio. García Basalo nota que no existía hasta 1925 un consenso acerca de una fecha determinada de inicio de las funciones de la prisión. Gómez eligió el 22 de mayo, cuando hubieran pasado cincuenta años de la aprobación del Reglamento Provisorio y sanción de la ley que completaba la organización del personal de la Penitenciaría Nacional. Cfr. García Basalo, Juan Carlos, "Medallística Penitenciaria 8) Cincuentenario de la Penitenciaría Nacional (1927)", Nueva Vida. Periódico cuatrimestral de la Asociación Mutual de Jefes y Oficiales Retirados del Cuerpo Penitenciario de la Nación, Vol. 2, n4, 1974, p. 12-17.

61. Sagarna, Antonio, "El trabajo en la Penitenciaría Nacional de Buenos Aires", Boletín de la Biblioteca Nacional de Criminología y Ciencias Afines, Vol. II, n5, 1927, p. 1.

62. Al menos desde la puesta en marcha de los talleres de la Penitenciaría Nacional, existió conflicto de intereses en torno a las escasas demandas del producto del trabajo de los penados desde las instituciones gubernamentales. Ver: García Basalo, Juan Carlos, Historia de la 
Penitenciaría de Buenos Aires (1869-1880), Ed. Servicio Penitenciario Federal, Buenos Aires, 1979, p. 189. y ss. Posteriormente, Gómez denunciará, en uno de los informes al Ministerio de Justicia, que esta situación permanecía sin muchos cambios cincuenta años después.

63. Sagarna, A., "El trabajo en la Penitenciaría Nacional", Op. Cit., p. 2.

64. Gómez, Eusebio, "El trabajo carcelario", Boletín de la Biblioteca Nacional de Criminología y Ciencias Afines, Vol. II, $n^{\circ} 5,1927$, p. 3.

65. La cifra no es nada desdeñable, considerando que la remuneración mensual por el cargo de director de la Penitenciaría Nacional ascendía a $\$ 650$, mientras que los puestos de menor importancia no pasaban de los $\$ 50$. La nómina completa de las colaboraciones es la siguiente: Ernesto Tornquist y Cía. Ltda.: \$2000; Piccardo y Cía. Ltda.: \$2000; Fábrica Argentina de Alpargatas S.A.: \$1000; Cía. General de Fósforos: \$1000; Cervecería Argentina Quilmes S. A.: \$1000; M. S. Bagley y Cía.:\$1000; Luis Colombo: \$500; Saint hermanos: \$500; Pini Hnos. Cía. Ltda.: \$500; Herbin Fréres: $\$ 500$; Fábrica Argentina de Tejidos de Punto: $\$ 500$; Alejandro Llauró e Hijos: $\$ 500$; Bazzolla Hnos.: \$500; La Argentina S.A.: \$500; Imp. y Exp. Henry Grenier y Cía.: \$500; Américo E. Aliverti: $\$ 300$.

66. Penitenciaría Nacional de Buenos Aires, Catálogo que presentan sus diversos talleres a la exposición industrial conmemorativa del cincuentenario de la fundación del establecimiento, Talleres Gráficos de la Penitenciaría Nacional, Buenos Aires, 1927, p. 7.

67. Cfr. González, E., “Circulación de saberes penales”, Op. Cit.

68. González Alvo, Luis, "Una aproximación a los orígenes de la administración penitenciaria federal. Las 'comisiones de cárceles' y el proyecto de reformas de Claros y Muratgia (1890-1912)”, Anuario del Instituto de Historia Argentina, Vol. 17, nº1, 2017, p. 19.

\section{RESÚMENES}

Este trabajo analiza la edición del Boletín de la Biblioteca Nacional de Criminología y Ciencias Afines, publicación dirigida por Eusebio Gómez, director de la Penitenciaría Nacional de Buenos Aires (1923-1928). Los escritos publicados en la revista nos permitieron comprender el contexto ideológico e institucional sobre el cual se pensó la administración penitenciaria en Buenos Aires durante los años veinte. La relectura de las producciones de Gómez a través de las revistas criminológicas previas revela la centralidad de la Penitenciaría Nacional como referencia de la cuestión penitenciaria local.

This paper analyzes the edition of the Boletín de la Biblioteca Nacional de Criminología y Ciencias Afines, a publication directed by Eusebio Gómez, director of the Buenos Aires National Penitentiary between 1923 and 1928. The writings published in the magazine allowed us to understand the ideological and institutional context on which the penitentiary administration in Buenos Aires was thought during the twenties. The rereading of Gómez's productions through the previous criminological journals reveals the centrality of the National Penitentiary as a reference of the local prison issue.

Cet article analyse l'édition du Boletín de la Biblioteca Nacional de Criminología y Ciencias Afines (1926-1929). Les écrits publiés dans la revue nous permettent de comprendre le contexte idéologique et institutionnel à partir duquel a été pensée l'administration pénitentiaire à Buenos Aires dans les années 1920. La relecture des productions de Gómez dans les revues 
criminologiques antérieures revèle la centralité du Pénitencier National comme référence de la question pénitentiaire locale.

\section{ÍNDICE}

Palabras claves: Eusebio Gómez, revistas penitenciarias, criminología, Buenos Aires, siglo XX Mots-clés: Eusebio Gómez, revues pénitentiaires, criminologie, 20e siècle, Buenos Aires Keywords: Eusebio Gómez, penitentiary journals, criminology, Buenos Aires, 20th century

\section{AUTOR}

\section{ESTEBAN GONZÁLEZ}

Profesor Universitario en Historia por la Universidad Nacional de General Sarmiento, Argentina. Estudiante del programa de Magíster en Ciencias Sociales, Instituto de Desarrollo Económico y Social/Universidad Nacional de General Sarmiento, Argentina. Doctorando en Historia, Universidad de San Andrés, Argentina. . Correo electrónico: edg998[at]gmail.com 